\title{
GIJÓN EN EL PERÍODO TARDOANTIGUO: CERÁMICAS IMPORTADAS DE LAS EXCAVACIONES DE CIMADEVILLA
}

\author{
POR
CARMEN FERNÁNDEZ OCHOA, PALOMA GARCÍA DÍAZ Y ALEXANDRA USCATESCU BARRÓN
Universidad Autónoma de Madrid

\section{RESUMEN}

Presentamos un lote de cerámicas tardorromanas hallado en las excavaciones de la ciudad de Gijón, relacionable con conjuntos arqueológicos similares de las costas inglesas, galesas y aquitanas.

Estos hallazgos confirman la importancia de Gijón dentro de la red comercial atlántica en el período tardoantiguo.

\section{SUMMARY}

This paper shows a collection of late Roman potteries found at Gijón (Asturias) during the recent archaelogical works, collection related to those from the English, Welsh and Aquitanian shores.

These finds confirm the important role of Gijón in the Late Roman atlantic trade.

\section{INTRODUCCIÓN}

\section{La unidad del lote cerámico y su origen}

El conjunto cerámico presenta como denominador común un carácter alóctono. Se trata de piezas de época tardorromana, de origen variado, que fueron importadas a Gijón desde distintos puntos del Mediterráneo y del Atlántico. 
En primer lugar el lote cerámico gijonés lo compone un importante conjunto procedente del norte de África: las denominadas terras sigillatas africanas $D$. En segundo lugar, una serie de importaciones orientales, reducidas a la terra sigillata focense tardía y a la denominada ánfora tardorromana tipo I de Cartago procedente de la zona de Antioquía. En tercer lugar, un abundante grupo de terras sigillatas grises gálicas tardías, procedentes del litoral atlántico francés. Y, por último, un pequeño grupo de cerámicas que se podrían denominar como imitaciones regionales de las terras sigillatas grises gálicas tardías, de origen incierto'.

\section{Procedencia de las piezas}

En el presente estudio se analizan un total de 49 piezas cerámicas halladas en el yacimiento urbano de Cimadevilla (Gijón). En este barrio antiguo de la ciudad se han localizado restos de estructuras correspondientes a una muralla tardorromana, a unas termas (siglos II-IV d.C.) y a un establecimiento dedicado a la explotación pesquera que funcionó entre los siglos III y IV $/ \mathrm{V}$ d.C.

Los ejemplares cerámicos objeto de nuestro estudio proceden en su gran mayoría de las Termas del Campo Valdés (Sector E). Estas fueron excavadas parcialmente en 1903 por el erudito local C. Alvargonzález. Desde 1990 se han llevado a cabo trabajos de recuperación y exhumación de las ruinas antiguas, así como la excavación sistemática de nuevas zonas por parte de C. Fernández Ochoa y P. García Díaz.

Dentro del sector E excavado en las Termas (fig. 1), concretamente en las denominadas cuadrículas Z-4 y Z-8 correspondientes a uno de los hypocausta del edificio termal, se localizó un importante depósito arqueológico, de aproximadamente unos $1,20 \mathrm{~m}$. de potencia, perteneciente a un «Horizonte» de finales del v d.C. primera mitad vi d.C. Dicho depósito se ubicaba sobre el suelo arrasado un hypocaustum y aparecía sellado, en su parte superior, por un estrato de época altomedieval. En este depósito además de t.s.a., t.s.g.g.t. y ánforas orientales, se determinó la existencia de un importante grupo de cerámica común, de origen incierto, aunque probablemente regional, que será objeto de análisis en ulteriores publicaciones.

Otro grupo de hallazgos cerámicos ( $n .{ }^{\circ}$ cat. $4,5,16,23,27$ y 34$)$ de estas termas, lamentablemente carece de contexto arqueológico, ya que provienen bien de niveles superficiales y alterados o bien de las antiguas excavaciones de 1903.

Por último tres fragmentos $\left(n .{ }^{\circ}\right.$ cat. 1,2 y 25$)$ procedentes de las distintas catas efectuadas en la muralla tardorromana (Sectores B y C) y sin contexto definido.

\section{Estudios peninsulares antiguos y recientes}

Las primeras investigaciones sobre las importaciones de este tipo de $t . s$. se remontan a inicios de este siglo. Concretamente la primera descripción fue publicada por L. Siret (1906,

${ }^{1}$ En el texto se utilizan las siguientes abreviaturas: t.s.a. (terra sigillata africana), t.s.f.t. (terra sigillata focense tạrdía), t.s.g.g.t. (terra sigillata gris gálica tardía) e imitación de t.s.g.t. (imitación de terra sigillata gálica tardía). 

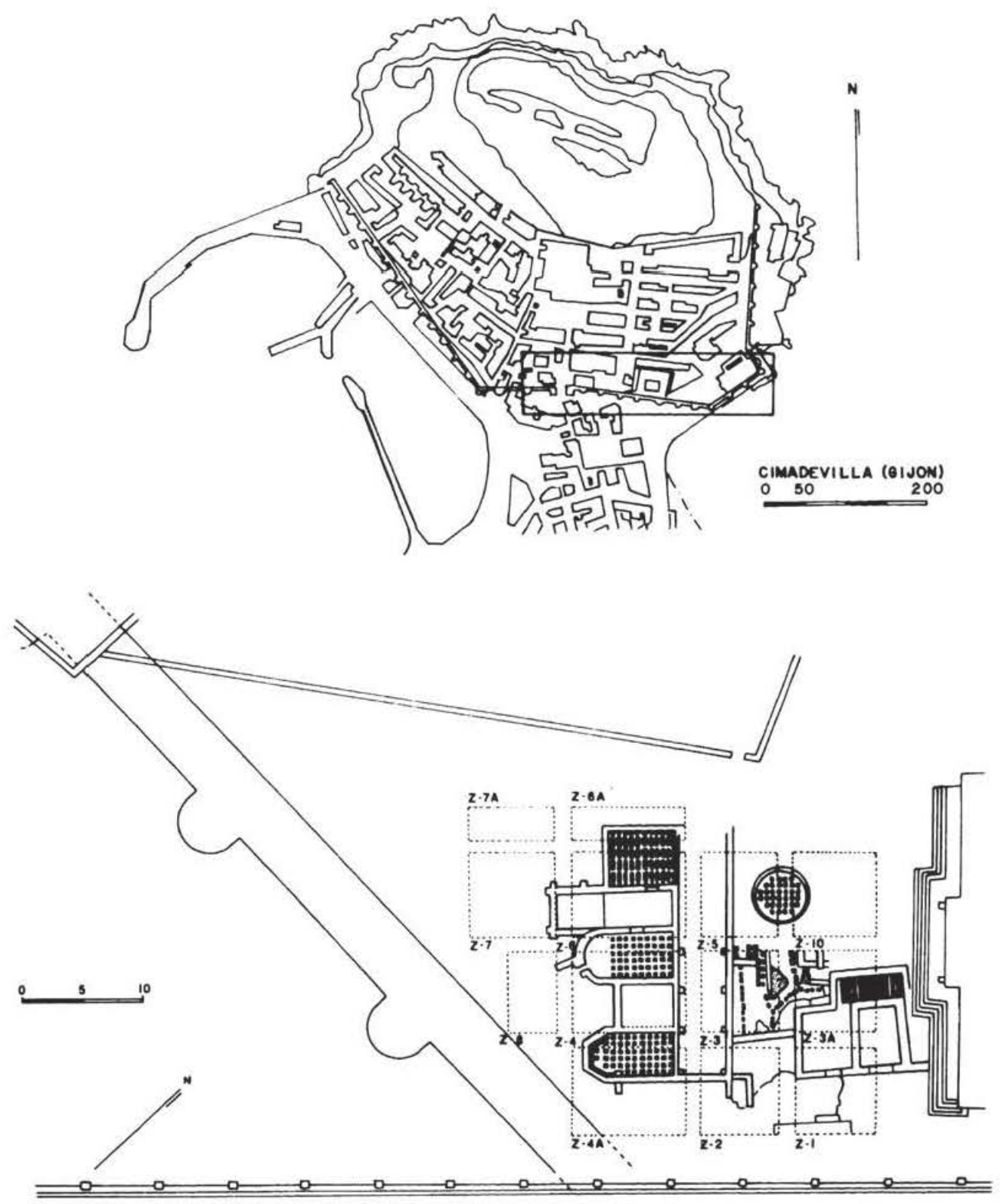

Figura 1.-Área excavada de Cimadevilla con la muralla y las termas y detalle de las termas de Campo Valdés. 
439). Este investigador intuyó un dato interesante sobre el posible origen de unos platos decorados hallados en las excavaciones del cerro de Montroy (Villaricos, Almería): "El hallazgo más interesante consiste en una serie de platos ó fuentes grandes, de un hermoso barro rojo, parecido al arretino, pero privado de ese brillo vivo tan característico", y continúa: "Nuestros platos rojos fueron, por consiguiente, importados y, probablemente, fabricados en Cartago, donde esta clase es abundantísima. Esta importación debió tener lugar cuando existían relaciones estrechas entre Cartago y estas costas, es decir, durante la corta duración de la dominación bizantina sobre estas provincias, en la última parte del siglo vı y principios del VII"? ?

Importantes también fueron los estudios sobre las t.s.g.t. de M. Cazurro (1909-1910) y H. Zeiss (1933), que se pueden considerar pioneros dentro de la investigación de esta variedad francesa de sigillata.

Por lo que respecta a las investigaciones peninsulares sobre estas cerámicas importadas de la antigüedad tardía, durante un tiempo parece que el interés por estas piezas decae hasta que a finales de la década de los años cuarenta P. de Palol publicó su estudio sobre las cerámicas estampadas romano-cristianas halladas en la Península (Palol, 1948). Un problema que plantea este estudio pionero es que engloba distintos tipos de importaciones bajo una misma denominación, tales como t.s.a. o t.s.g.t. Aunque Palol ya definió claramente el origen norteafricano de alguna de las estampillas (Palol, 1948, 465-466).

Durante las décadas de los años cuarenta a los sesenta la investigación peninsular recibe un fuerte empuje tras la publicación de los distintos trabajos de N. Lamboglia $(1941,1958,1963)$ sobre las, entonces, denominadas «terre sigillate chiare" y el de J. Rigoir (1968) sobre las «sigillées paléochrétiennes grises et orangées».

Las tendencias investigadoras de la década de los años setenta están encabezadas por la figura de L. Caballero $(1966,1972,1974)$, autor de las primeras obras peninsulares sobre t.s.a. y t.s.g.t. (grises y anaranjadas) y G. Martín (1965, 1966, 1968 y 1969). En Portugal, M. Delgado (1967), A. y J. Alarcão (1963-1964) y J. J. Rigaud (1966-1967) son los investigadores más destacados en este campo. En este período la investigación peninsular se enmarca dentro de la coriente latina, encabezada por $\mathrm{N}$. Lamboglia. Mientras que los investigadores anglosajones continuaron empleando los trabajos más significativos publicados al respecto hasta la fecha (Waage, 1933; Hayes, 1972).

No será hasta los años ochenta, como hemos indicado en otro lugar (Alonso y Fernández Ochoa, 1988, 353-354), sin duda influenciados por la publicación del Atlante delle forme ceramiche I (VV.AA., 1981) dirigido por A. Carandini, cuando los estudiosos espanoles se interesen por esa misma obra y se comience a emplear la tabla tipológica de J. W. Hayes (1972 y 1980). El resultado ha sido una eclosión en la publicación de nuevos hallazgos de t.s.a., t.s.f.t., t.s.g.t., ánforas orientales y producciones regionales que imitan las t.s. importadas (Méndez Ortiz, 1983-1984; Keay, 1984; Reynolds, 1984; Vázquez, 1985; Járrega, 1987; Reynolds, 1987; Méndez Ortiz, 1988; VV.AA., 1989; Bourgeois y Mayet, 1991; Járrega, 1991; Naveiro, 1991; Paz, 1991; etc.).

${ }^{2}$ L. Siret engloba en un mismo lote importado a las t.s.a. (Siret, 1906, Lám. XXIX, n. 1 y n.* 5-7) y a las t.s.f.t. (Siret, 1906, Lám. XXIX, n. ${ }^{\text {os }} 2-4$ ) atribuyéndoles un mismo origen en Cartago. 


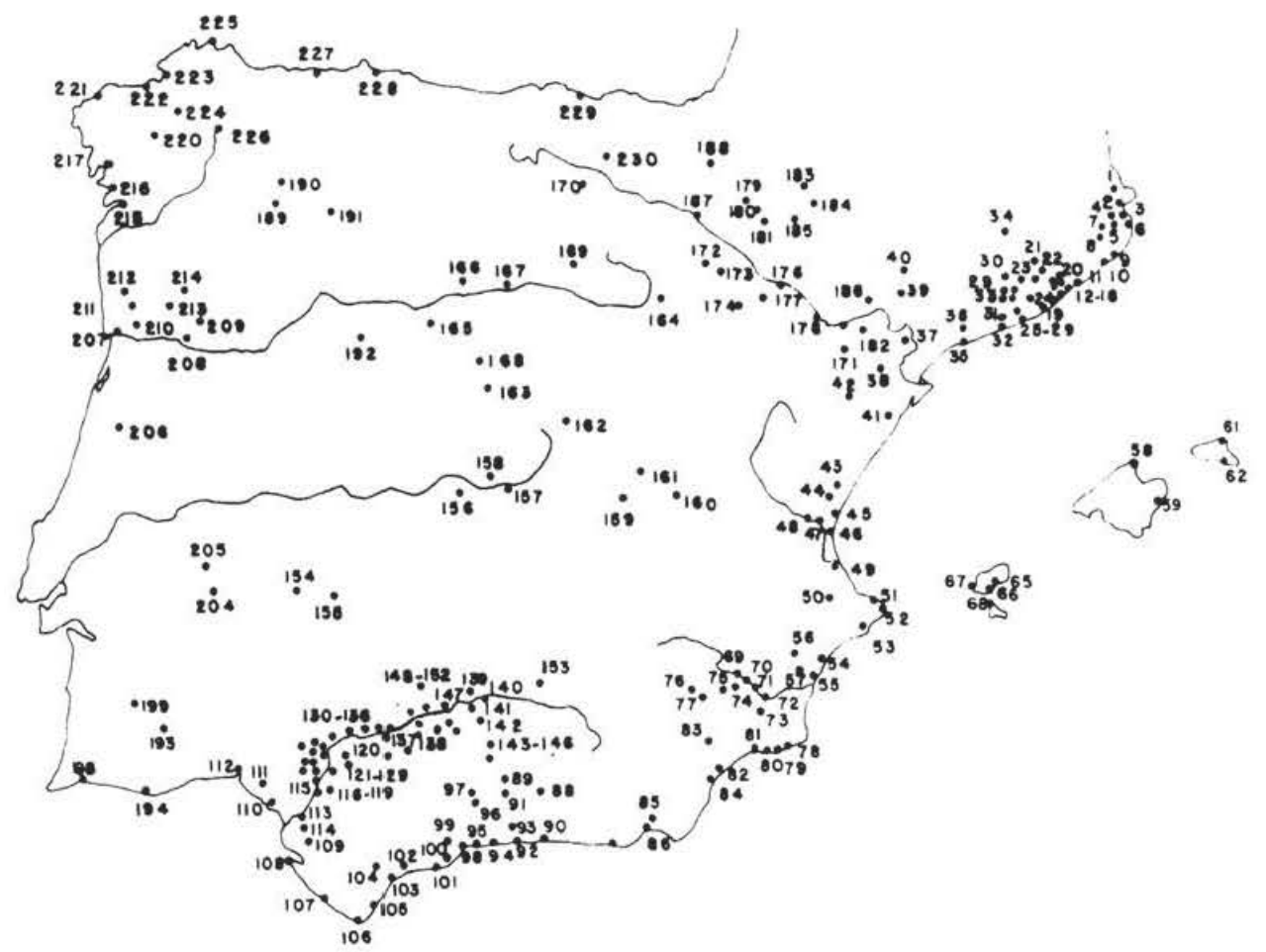

Figura 2.-Mapa de dispersión peninsular de la Terra Sigillata Africana D.

\section{ESTUDIO}

El estudio que presentamos a continuación se ha estructurado de acuerdo con la zona de origen de las piezas: norte de África, costa microasiática (Focea y región de Antioquía del Orontes) y litoral atlántico francés (Burdeos).

Para la clasificación tipológica de las piezas hemos adoptado las tipologías más habituales y aceptadas, en concreto la de J. W. Hayes (1972) para las t.s.a. y t.s.f.t., y la de J. Rigoir (1968) para las producciones gálicas tardías.

Más complicado nos ha resultado el estudio taxonómico de las ánforas orientales, por lo que hemos incluido las distintas denominaciones que reciben este tipo de contenedores en las diferentes tipologías publicadas (Peacock y Williams, 1986).

\section{Terra sigillata africana}

Muchas han sido las denominaciones que han tenido este tipo de producciones, originarias de Túnez. La primera fue la de F. O. Waagé $(1933,279)$ que las llamó Late Roman $A$ y $B^{3}$, atendiendo, fundamentalmente a los distintos tipos de estampillas. Años más tarde y, sobre todo en occidente, se conocieron con el nombre de terra sigillata chiara (Lamboglia, 1953 y 1963). En

${ }^{3}$ Esta clasificación es la que siguieron los autores que investigaban en el Mediterráneo Oriental. 
1972, J. W. Hayes acuñó el término de African Red Slip Ware, que hacía referencia a su zona de producción, negando el origen egipcio propuesto anteriormente (Waagé, 1933, 293). Actualmente no hay ningún problema en aceptar la nomenclatura de t.s.a., propuesta por la escuela de Carandini (VV.AA., 1981).

La primera vez que se dieron a conocer este tipo de importaciones en Gijón fue a principios de siglo cuando $C$. Alvargonzález recogió una serie de piezas halladas en las excavaciones de las Termas del Campo Valdés (figs. 17,41-42 y 44), pero que definió como «barros saguntinos» (Alvargonzález, 1965, 62). Con esta denominación, este autor, englobó tanto a las t.s. hispánicas como a las africanas (Alvargonzález, 1965, 61). En 1977 se publicó una revisión de las piezas cerámicas de las Termas intentando identificar correctamente los distintos tipos cerámicos dibujados por C. Alvargonzález (Maya, 1977, 826-827).

El nuevo lote que aquí presentamos procede de las últimas excavaciones en la muralla de Gijón ${ }^{4}$ y de los más recientes hallazgos, hasta la fecha inéditos, de las Termas del Campo Valdés.

Todas las $t$.s.a. localizadas en Gijón pertenecen a la producción $\mathrm{D}^{5}$, fabricada en las oficinas de Túnez septentrional (Hayes, 1977, 280) desde finales del siglo III d.C. o inicios del siglo IV d.C. hasta el siglo VII d.C. (VV.AA., 1981, 14), que es sin duda el tipo más extendido por todo el Mediterráneo (Salomonson, 1968, 90). Dentro del conjunto de Cimadevilla hemos hallado productos de distintas fases de estos alfares del norte de Túnez, en concreto de la producción $D_{1}$, caracterizada por un engobe con poco brillo o casi mate y de la fase primera de la producción $\mathrm{D}_{2}$, versión algo más tosca, en general, y con un engobe más espeso (VV.AA., 1981, 14).

\section{a) Forma $73 \mathrm{~A} / 70$ var. de Hayes}

Esta forma (figs. 17, 41) sólo la conocemos por la publicación de C. Alvargonzález (1965, Lám. XXVII, fig. 30). J. L. Maya la consideró como una producción de t.s.a. $C$ de una fase tardía del taller de fabricación de la C (Maya, 1977, 827), identificación que también aceptó R. Járrega (1991a, 11). Pero esta identificación es difícil de confirmar ya que sólo contamos con los magníficos dibujos de C. Alvargonzález y sus poco clarificadoras descripciones (Alvargonzález, 1965, 62).

Ante la imposibilidad de analizar directamente esta pieza siempre quedarán dudas sobre su verdadera adscripción a la producción $\mathrm{D}$ o a la $\mathrm{C}$. En este último caso sería la única pieza del conjunto de Cimadevilla perteneciente a los alfares de la Bizacena.

En Belo existen una serie de formas como la 71 y la 73 Hayes que se sitúan entre la fase final de la producción $\mathrm{C}_{4}$ y la $\mathrm{D}_{1}$; Bourgeois y Mayet $(1991,269)$ denominaron este tipo de producción como C/D, y corresponde a la t.s.a. E del Atlante I (VV.AA., 1981, 119) de la primera mitad del siglo $\mathrm{V}$ d.C. Una producción semejante se detectó en Conímbriga (Bourgeois y Ma-

${ }^{4}$ Sólo dos de las piezas que aquí estudiamos han sido publicadas previamente (Alonso y Fernández Ochoa, 1988) los números de catálogo 1 y 2; el resto es inédito.

5 Consideramos que las piezas publicadas por $\mathrm{C}$. Alvargonzález pertenecen a la producción $\mathrm{D}$, al igual que las recientemente descubiertas en las excavaciones de la Muralla y las Termas de Cimadevilla. A pesar de que R. Járrega $(1991 \mathrm{a}, 94)$ menciona una pieza procedente de Gijón de $t . s . a$. E, en el artículo de J. L. Maya (1977), en el que se basa ese autor, no aparece mencionada ninguna pieza parecida, ni siquiera la hemos encontrado en el libro de C. Alvargonzález (1965). 


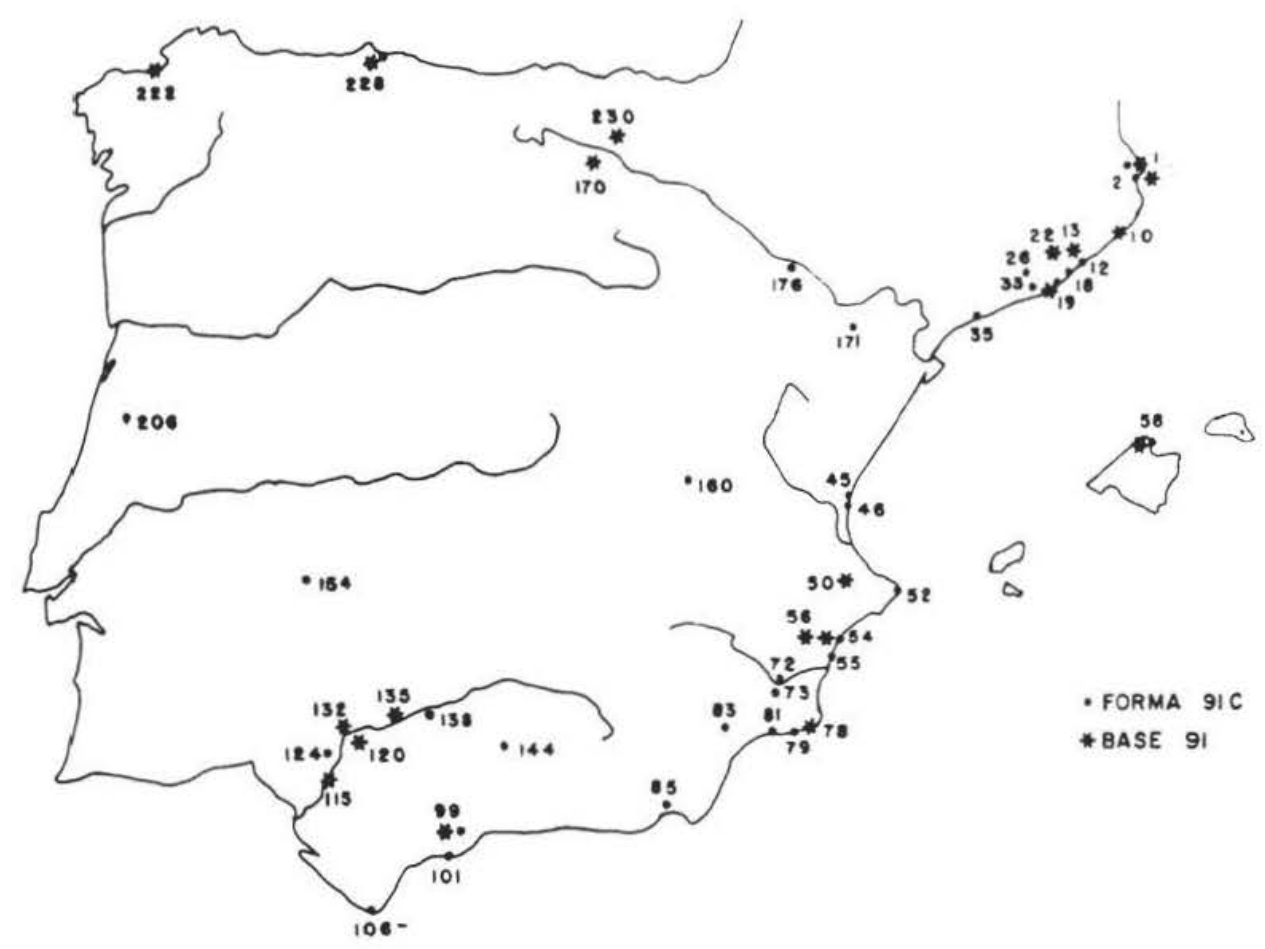

Figura 3.-Mapa de dispersión de la forma 9lC Hayes y bases decoradas a ruedecilla de la forma 91 Hayes de Terra Sigillata Africana D.

yet, 1991, 276), mientras que en Torralba (Lorca, Murcia) se incluye sin mayores problemas dentro de la producción D (Martínez y Matilla, 1988, 510).

Morfológicamente este borde de cuenco resulta problemático, parece similar a la forma 73A de Hayes (1972, fig. 21, 2), pero esta variedad se caracteriza por presentar el borde liso, sin ningún tipo de decoración (Hayes, 1972, 123) y en cambio la pieza $n .^{\circ} 41$ de nuestro inventario se caracteriza precisamente por la presencia de dos bandas paralelas impresas a ruedecilla. En cambio, existe otra forma, la variante de la forma 70 de Hayes $(1972$, fig. 21, 9) que es similar y además presenta una decoración a ruedecilla en la parte superior externa del borde, tal y como muestra la pieza en estudio (fig. 17, 41). En Els Prats de Rei (Barcelona) se halló una forma 73A, fabricada en C con decoración de ruedecilla en el borde (Járrega, 1991b, 52, fig. 2, 5).

La cronología, como es lógico, dependerá de la clasificación tipológica de esta pieza. La forma 73A Hayes se fecha entre 420-475 d.C. (Hayes, 1972,124) y está atestiguada su producción en el tipo D del alfar de El Mahrine, a unos 50 kilómetros al oeste de Cartago (Mackensen, 1985, 30) de donde, como se verá más adelante, proceden otras piezas de Gijón (fig. 10, 1-2). La variante de la forma 70 de Hayes, sin embargo, tiene una cronología más antigua, fechándose desde finales del IV d.C. a inicios del v d.C. (Hayes, 1972, 119).

Ante la imposibilidad de revisión directa de esta forma y su identificación como producción $\mathrm{C}_{4}$ o $\mathrm{D}_{1}$, debemos contentarnos con situarla cronológicamente en el siglo $\mathrm{V}$ d.C. 
b) Forma $91 \mathrm{C}$ Hayes

Son dos las piezas pertenecientes a esta forma (figs. 11,3 y 17, 42) denominada cuenco con pestaña ("flanged-how'/) (Hayes, 1972, 140) o cuenco con listel (Caballero, 1966, 153).

La primera pieza fue publicada por C. Alvargonzález (1965, Lám. XXVII, fig. 32) e identificada por J. L. Maya (1977, Lám. V, fig. 32) con la forma 91C Hayes. El nuevo ejemplar (fig. 11,3 ) de las termas pertenece al tipo $\mathrm{D}$, producción que se fecha desde finales del $\mathrm{V}$ a mediados del VI d.C. (VV.AA., 1981, 14). La pieza de Gijón pertenecería a la primera fase de la producción $\mathrm{D}_{1}$ (VV.AA., 1981, 78-79), que continúa con la tradición de la $\mathrm{A}_{2}$ (Bourgeois y Mayet, 1991, 292), caracterizada por pastas finas y engobes lustrosos de colores rojo-anaranjado o naranja ladrillo.

Según J. W. Hayes $(1972,144)$ sería una de las variantes más tardías de este tipo de cuencos. Este autor la fechó, en un principio entre 530-600 d.C., cronología que también se mantuvo en el "Atlante delle forme ceramiche I (VV.AA., 1981, 106, Tav. XLIX, 6). Años más tarde Hayes reconoció que el inicio general de la forma 91 debía situarse a finales del siglo IV d.C. (Hayes, 1976, 86).

El cambio de fechas fue producido por las subsiguientes investigaciones en Cartago, que modificaron la fecha inicial de esta forma. La misión italiana advirtió que esta forma aparecía ya en contextos finales del siglo IV e inicios del V (Tortorella, 1982, 127). La mayoría procedía de niveles anteriores a la construcción del muro de Teodosio II (400-425 d.C.). En otros yaci-

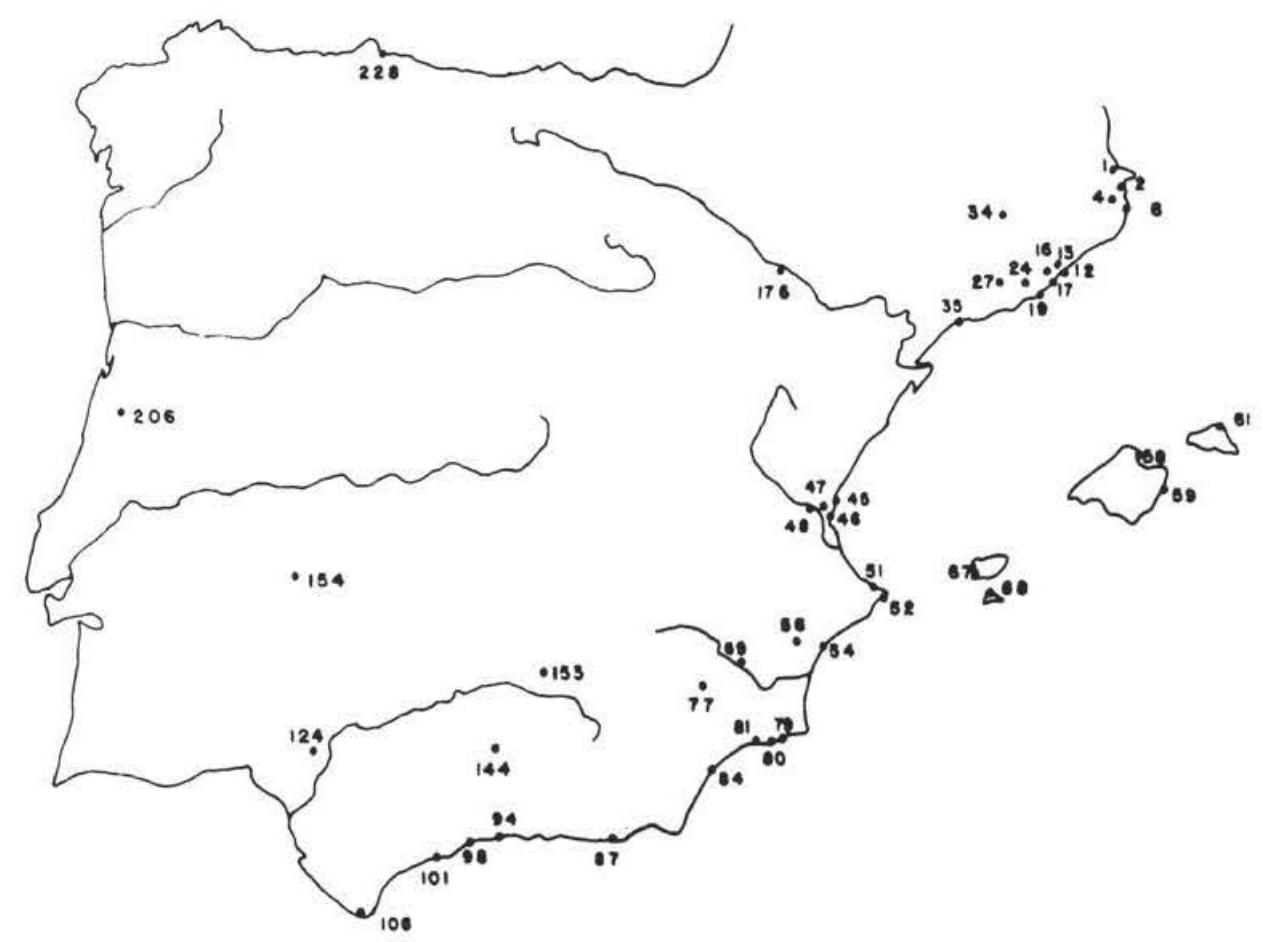

Figura 4.-Mapa de dispersión de la forma 99 Hayes de Terra Sigillata Africana D. 
mientos norteafricanos ocurría lo mismo pues en Sitifis (Sétif, Argelia) aparecía antes del 400 d.C., y por tanto, estaba ya presente antes de la conquista vándala (Hayes, 1977, 281).

En las excavaciones de la Universidad de Michigan en Cartago aparecieron ejemplares tempranos de la variante 91C Hayes en un depósito de finales del siglo IV d.C. (Hayes, 1976, 68, fig. 8, 10-11), por lo cual la fecha de 530 como inicio de la producción de esta variante, ya no se puede mantener. Dichos ejemplares continúan apareciendo entre finales del siglo $\mathrm{V}$ e inicios del vi d.C. (Hayes, 1976, 54-56).

En la Península Ibérica es una de las formas de africanas mejor representadas (fig. 3) y parece hallarse en las costas españolas desde, por lo menos, mediados del siglo $V$ d.C. En Valencia, la forma $91 \mathrm{C}$ es considerada como una de las series más tempranas de formas tardías (Reynolds, 1984, 480). En Murcia sin llegar al siglo v d.C., se fechan entre 525-550 d.C. (Méndez Ortiz, 1988, 107-108). En la ciudadela de Rosas se sitúan en el siglo VI d.C. (Nolla-Brufau, 1984, 446). En Maians (Bergas, Barcelona) esta forma parece típica del siglo VI d.C. (Járrega, 199 (b, 71) aunque en Cataluña estas piezas comienzan a documentarse desde la segunda mitad del siglo v d.C. (VV.AA., 1989, 137-138). Otros autores corrigen la cronología dada por Járrega a la pieza de Maians diciendo que el conjunto en el que se encuentra puede datarse entre el siglo IV d.C. y la primera mitad del siglo v d.C. (Daura y Pardo, 1991, 44). En Conímbriga, al parecer, no aparecen en niveles de mediados del siglo $\vee$ d.C. (Delgado, Mayet y Mountihno, 1975, 260) y sí después. En Belo es la sexta forma de la producción D en importancia. En este yacimiento se empleó, para su datación, la propuesta por Hayes, aunque recortada por Fulford (Bourgeois y Mayet, 1991, 304). Las piezas de Málaga se han fechado según la antigua cronología propuesta por Hayes del 530-600 d.C. (Serrano y Luque, 1980, 266), al igual que la del Castillo de Garres en Murcia (Matilla, 1988, 376), las de Mazarrón (Pérez, 1988, 510 y 512), las de Torralba (Lorca, Murcia) (Martínez y Matilla, 1988, 512) o las de Mérida, fabricadas en el tipo $\mathrm{D}_{2}$ (Vázquez, 1985, 28).

La cronología de la forma 91C de Hayes en la Península Ibérica, tras los nuevos datos estratigráficos que tenemos sobre la presencia de estos cuencos en distintos yacimientos del Mediterráneo, tiende a ser considerada como demasiado tardía. Actualmente se pueden llevar algunos ejemplares peninsulares de la forma $91 \mathrm{C}$ Hayes a la segunda mitad del siglo $\mathrm{V}$ d.C. (Járrega, 1991a, 62).

Las piezas de Gijón, no tan tempranas como los ejemplares de Cartago (Hayes, 1976, fig. 8 , 10-11) pueden fecharse entre finales del siglo $v$ d.C. $y$ mediados del VI d.C. como parece desprenderse de las características de su manufactura, perteneciente al tipo $\mathrm{D}_{1}$.

\section{c) Forma 99 Hayes}

Por su estado fragmentario no podemos adscribir esta pieza a ninguna de las variantes observadas por Hayes, ya que esta subdivisión se realizó por la relación existente entre la medida del diámetro del borde y del diámetro de la base (Hayes, 1972, 152), y la pieza de Gijón (fig. $11,4)$ es sólo un borde, por lo que pudo pertenecer tanto a un cuenco de la forma $99 \mathrm{~A}$ como a uno de la 99B.

Este fragmento de cuenco pertenece a la producción $D_{2}$, ya que presenta un engobe semilustroso y más grueso que la anterior producción $\mathrm{D}_{1}$ (que recuerda en cierto modo al de la $\mathrm{A}_{2}$ ), 
y bastante alterado. La pasta es más grosera con inclusiones de calcita. Pertenecería a una fase tardía de esta producción, datada entre finales del siglo $\mathrm{V}$ y el siglo VII d.C.

La cronología propuesta por J. W. Hayes $(1972,155)$ del 510 al 580 d.C. nuevamente se vio alterada con los descubrimientos de la misión de la Universidad de Michigan en la misma Cartago donde, en el depósito VII, se halló un plato de la forma 99A fechable, todo el conjunto, desde finales del siglo $\mathrm{V}$ a inicios del VI d.C. (Hayes, 1976, 87).

En cambio, las cronologías que tienen este tipo de piezas en la Península Ibérica se acercan bastante a la primera propuesta de J. W. Hayes. En Cartagena hay ejemplares, también de la producción $D_{2}$ (Méndez Ortiz, 1988, 116) fechados entre 510 y 540 d.C. (Méndez Ortiz, 1988, 119), así como en el Castillo de los Garres (Murcia) (Matilla, 1988, 383). Otros ejemplos son los del Llano del Olivar (Aljezares, Murcia), cerro del Fuerte (Rioja, Almería) (Caballero, 1974, 205), los de Villar de Zagrilla (Priego, Córdoba) (Vaquerizo, Murillo y Quesada, 1991, fig. 16) o la de la Alcazaba de Mérida en el tipo $D_{2}$ (Vázquez, 1985, 61) fechados desde inicios del siglo VI d.C., aunque Vázquez ya apunta la posibilidad que pudo aparecer en el siglo v d.C.

Los ejemplos más tardíos son los de la ciudadela de Rosas, cuya cronología se sitúa bien entrado el siglo VI d.C. (Nolla-Brufau, 1984, 447), el de Roca Roja (Berga, Barcelona) del siglo VI d.C. (Daura y Pardo, 1991, 45) y los de Valencia de finales del siglo VI d.C. (Reynolds, 1984, 478). Como vemos es una forma bien representada en la Península Ibérica (fig. 4).

La pieza de Gijón ostentaría una cronología general asignable al siglo vi d.C.

\section{d) Forma 104 Hayes, variante de Gijón}

Estas dos piezas fueron objeto de un estudio monográfico anterior (Alonso y Fernández Ochoa, 1988) y fue clasificada preliminarmente como la forma $104 \mathrm{~A} / \mathrm{B}$ de Hayes (Alonso y Fernández Ochoa, 1988, 339).

Nuevas investigaciones nos han llevado a profundizar en la clasificación anteriormente propuesta. Si bien, su adscripción a la primera fase de la producción $\mathrm{D}_{2}$ fechada desde el siglo $\mathrm{V}$ d.C. a inicios del VI d.C. caracterizada por un engobe brillante y muy pulido (VV.AA., 1981, 14) es correcta, su clasificación como forma $104 \mathrm{~A} / \mathrm{B}$ Hayes puede matizarse ${ }^{6}$. En el dibujo que aquí publicamos (fig. 10,1) se muestra claramente su borde «escalonado» en el interior, que difícilmente se puede clasificar dentro de los estudios taxonómicos existentes (Hayes, 1972; VV.AA., 1981). Morfológicamente debiera situarse entre la forma 104 Hayes, por el perfil de la pared y su pie, en general y, la forma 105 de Hayes, más próxima a la de Gijón, por su borde «escalonado».

En Belo ocurre algo similar pues en este yacimiento es difícil distinguir entre la forma 104 y 105, lo que hace que muchos bordes se clasificaran como 104/105 (Bourgeois y Mayet, 1991, 307). Además, no siempre ha sido posible, en Belo, distinguir entre las tres variantes de la 104 de Hayes.

\footnotetext{
${ }^{6}$ En el dibujo publicado (Alonso y Fernández Ochoa, 1988, fig. 12, 66), por problemas en la impresión del mismo no se apreciaba con la suficiente nitidez la forma del borde y la estampilla. Esta última, en cambio, sí se apreciaba con claridad en las láminas I y II de ese mismo artículo.
} 


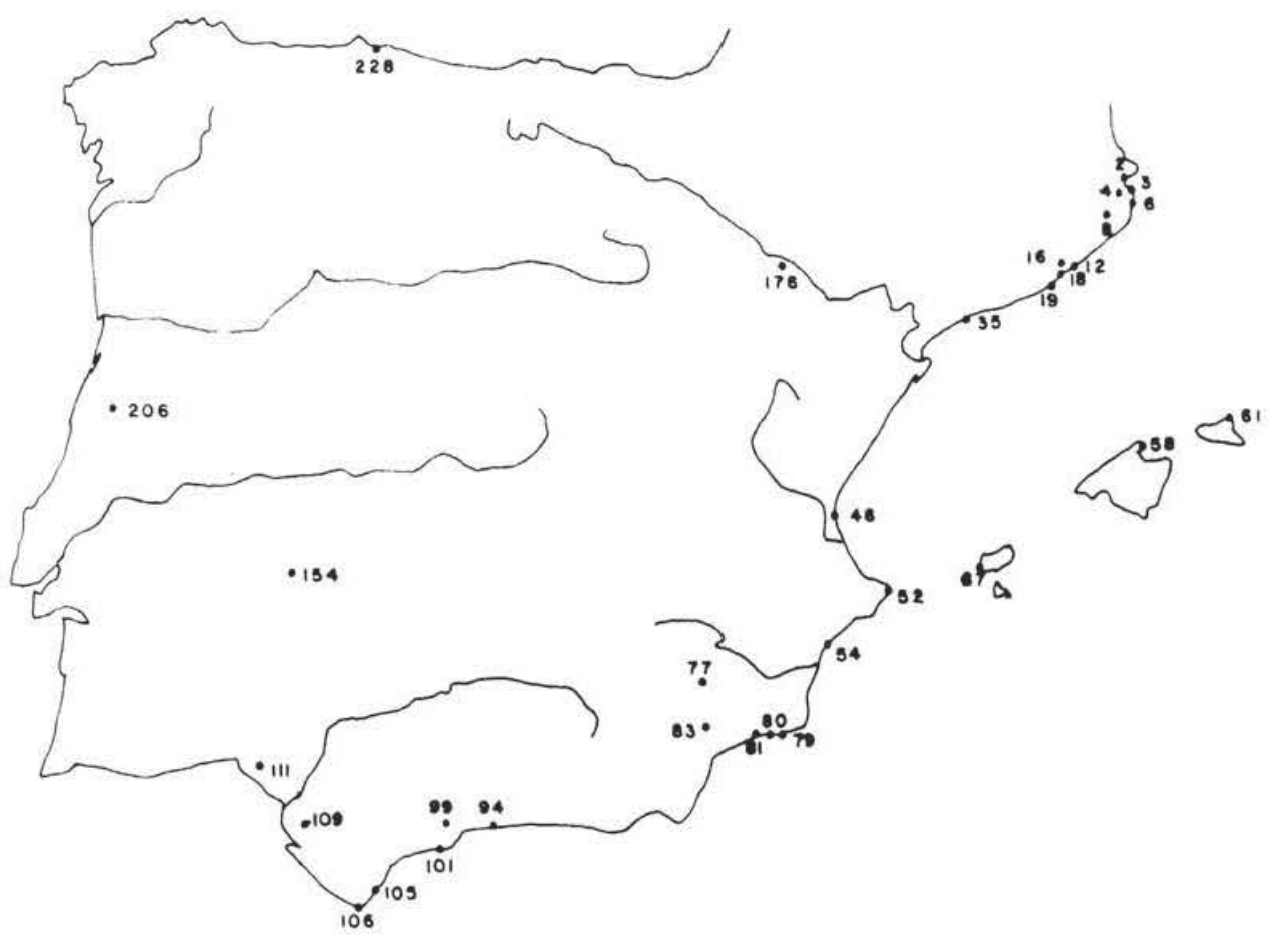

Figura 5.-Mapa de dispersión de la forma 104 Hayes de Terra Sigillata Africana D.

En cuanto a la estampilla con crismón inscrito en un corazón y dos motivos en « $\mathrm{S}$ » a cada lado del crismón (fig. 18, 1) pertenece al estilo A(ii)/E(i) transicional de Hayes; estilo fechado de forma general entre el $450 \mathrm{y}$ el 480 d.C. Se conocen estampillas similares en Istria (Rumanía) (Alonso y Fernández Ochoa, 1988, 363), y en la Península Ibérica los tenemos en Lucentum (Reynolds, 1987, n. ${ }^{\circ} 661$ ) y en Belo (Ponsich, 1980, Lám. VII; Bourgeois y Mayet, 1991, Pl. CXI, 541). Un motivo idéntico es el punzón que se empleó en el alfar de El Mahrine (Mackensen, 1985, Abb. 6, 155, estampilla tipo 67), a unos $50 \mathrm{~km}$. al oeste de Cartago, oficina que estaba especializada en la producción $\mathrm{D}_{1}$ (Mackensen, 1985, 29). El punzón se fecharía en la segunda fase de este alfar, que es probable que iniciara ya la producción tipo $\mathrm{D}_{2}, \mathrm{y}$ que se fecharía entre el 460 y 480 d.C. (Mackensen, 1985, 32).

En Gijón tenemos una segunda pieza perteneciente también a la variante 104 (fig. 10,2), que fue hallada durante las excavaciones de la muralla de Cimadevilla. Este fragmento de borde resulta problemático; por su forma y características externas pertenece a la misma forma que el plato anterior, aunque es ligeramente diferente en algunos aspectos que habría que matizar: el engobe, aplicado en el interior y en el exterior del borde sólo llega hasta el exterior del borde inferior, no como el plato casi completo (fig. 10,1), donde el engobe ocupa mayor espacio en el exterior y su diámetro y grosor general es algo mayor. De ahí que se hayan considerado como dos piezas distintas.

En cuanto a la cronología, si la adscripción de estas piezas a la oficina de El Mahrine es cierta, debemos situarlas entre el 460 y el 480 d.C. 


\section{e) Bases decoradas de Terra sigillata africana D}

La primera (fig. 17, 44) fue publicada con anterioridad (Alvargonzález, 1965, Lám. XXVIII, fig. 34; Maya, 1977, Lám. V, fig. 34) e identificada como una base decorada a ruedecilla de la forma 91 de Hayes (Maya, 1977, 827; Járrega, 1991a, 66-67), pero al carecer de la documentación gráfica de la sección de la base no podemos adjudicarla a ninguna de las variantes de Hayes y, por tanto, su cronología es también imprecisa: de finales del siglo $\mathrm{V}$ d.C. al siglo VI d.C., sin poder precisar nada más sobre esta pieza.

En el lote de Gijón, aparte de la estampilla del plato de la forma 104 variante, de un crismón inscrito en un corazón analizado líneas arriba, existe otro motivo (fig. 11,6) compuesto por un punzón, presumiblemente dispuesto en círculo en series repetitivas en el interior de un plato de t.s.a. D, Este motivo definido como serie de tres círculos concéntricos con orla punteada ( $d o t$ fringes») del estilo A(ii)/(iii) de Hayes, se fecha entre finales del siglo IV y mediados del VI d.C. (Hayes, 1972, 236, fig. 40, 32n).

\section{f) Difusión peninsular de las terras sigillatas africanas D}

Con los últimos hallazgos peninsulares (figs. 3, 4 y 5), incluidos los de Gijón, parece confirmarse la hipótesis que años atrás emitió J. Salomonson $(1968,90)$ sobre la difusión de la t.s.a. $D$ que resulta ser mucho más amplia de lo que se pensaba (fig. 2).

Cronológicamente la máxima difusión de la $t$.s.a. se da desde finales del siglo v d.C. a la primera mitad del siglo vi d.C. (Tortorella, 1986, 213). Esta máxima difusión, según Tortorella coincide con una mayor variedad de formas, tras la reconquista de Justiniano del norte de África (Tortorella, 1986, 219). Este panorama también se observa en la Península Ibérica, donde por ejemplo, la mayor parte de las piezas pertenecen a la D.

En la Península Ibérica y las Baleares la presencia de este tipo de importación está atestiguada a lo largo de todo el litoral mediterráneo, atlántico y cantábrico y, en menor medida, en el interior, a lo largo de las vías fluviales más importantes: Guadalquivir, Ebro, Duero y Tajo.

Lo que resulta muy significativo es la presencia de estas importaciones en el litoral Cantábrico, aunque no son muy abundantes. Hasta ahora sólo se conocen las de Gijón y la problemática pieza de Flavióbriga (Castro Urdiales, Santander) que al parecer pertenece a la forma 69 de Hayes ? . Más al interior tenemos las piezas de Iruña y Pamplona. Según R. Járrega (1991a, 92) es a finales del IV o principios del v d.C. cuando los productos africanos alcanzan el litoral can-

7 En la publicación de Flavióbriga, Solana (1977, 35-36) no expresa claramente la adscripción del plato a una producción africana. Este autor dice literalmente: «S. IV-V: Disponemos de algunas piezas de este período. Dos platos de terra sigillata que corresponden a las formas Hispánica 49 e Hispánica 6. El primero debe identificarse con la forma 69 de Hayes que data del segundo cuarto de siglo V》. En este párrafo, confuso por el empleo de dos tipologías, una para producciones hispánicas y otras para africanas, el plato en cuestión jamás aparece mencionado como una producción africana y sí, en cambio, como forma hispánica.

La descripción de Mañanes $(1980,231)$ de ese plato «...cuya forma oscila entre la Hispana 49 y la Hayes 59 y la T.S.H. tardía de Palol ", nos hace pensar que quizá se trate de una producción hispánica y no una importación africana. 
tábrico y continúan importándose durante la segunda mitad del siglo $\mathrm{V}$ y primera mitad del $\mathrm{VI}$ d.C., dato que se confirma claramente con los ejemplares de Gijón.

\section{Terra Sigillata focense tardía}

La nomenclatura de este tipo de producciones resulta problemática y polémica. En los primeros momentos fue conocida en oriente como "Late Roman $C$ Ware", término acuñado por F. O. Waagé (1933, 279). Años más tarde J. W. Hayes mantuvo esta denominación, hasta 1980, y propuso un origen en la región de Pérgamo o Çanakkanale (Hayes, 1972, 369-370; VV.AA., 1981, 232). Este mismo autor le cambió el nombre al hallarse el alfar productor de estas cerámicas en Focea, localidad turca situada entre Esmirna y la antigua Pérgamo, proponiendo el nombre de «Phocaean Red Slip Ware» (Hayes, 1980, 525), que es el nombre más extendido. Aunque también se la denominó t.s. de Asia menor o de Constantinópolis (VV.AA., 1981, 231).

Los autores españoles y portugueses han empleado directamente el término inglés, tanto el de "Late Roman C" (Méndez Ortiz, 1983-83) como el de "Phocaean Red Slip Ware» (Nieto,

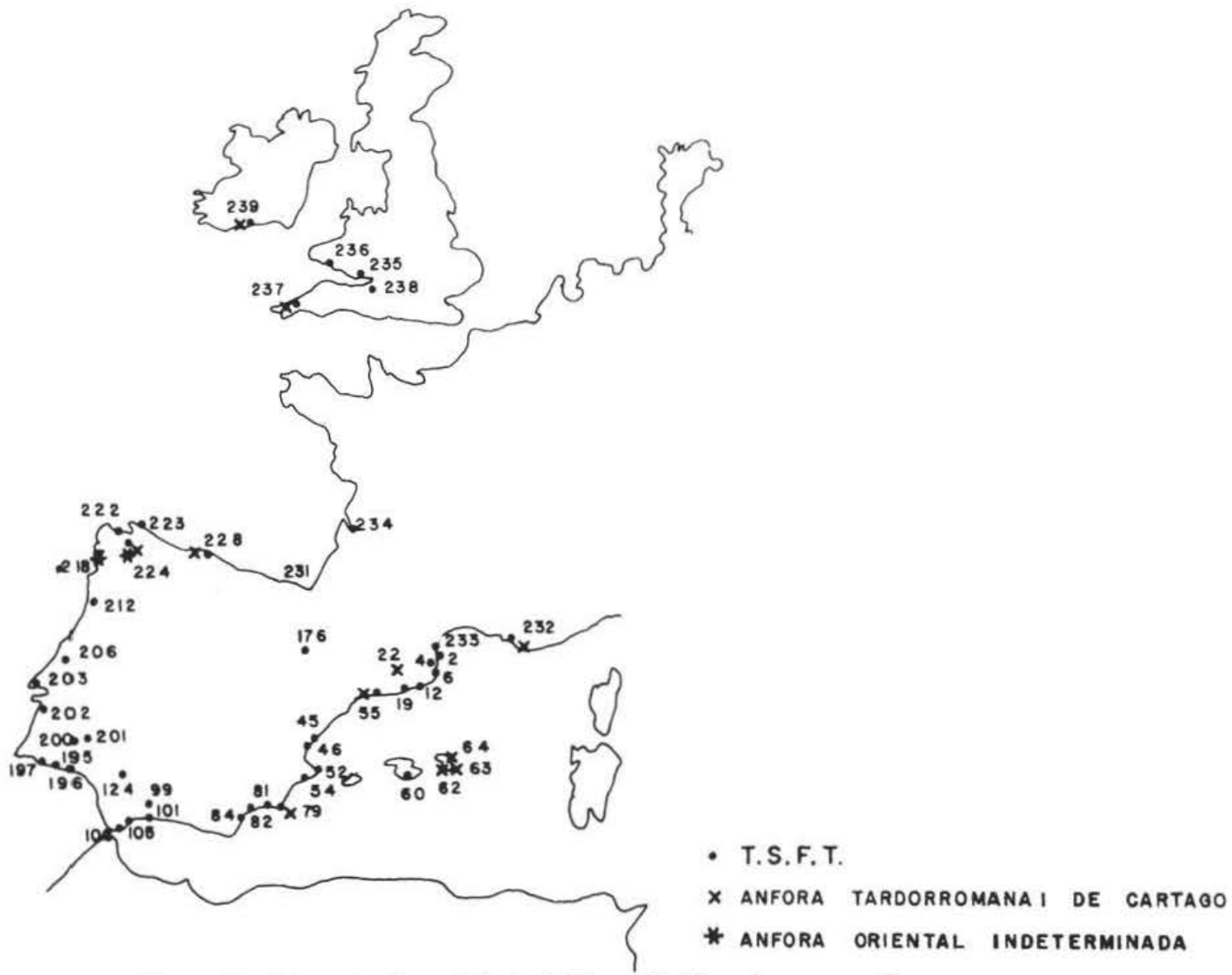

Figura 6.-Mapa de dispersión de la Terra Sigillata focense tardía y del ánfora tardorromana tipo 1 de Cartago. 


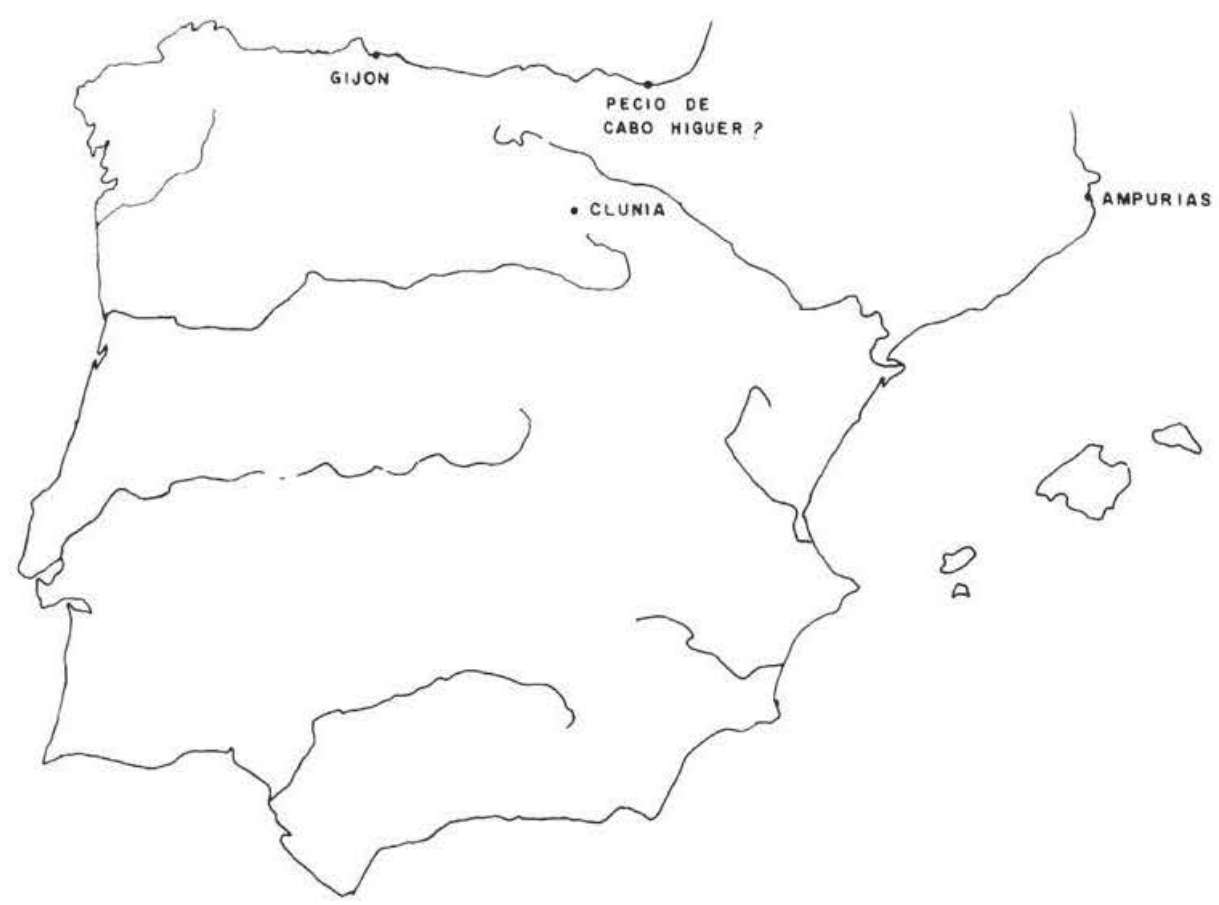

Figura 7.-Mapa de dispersión de la Terra sigillata gris gálica tardía.

1984; Paz, 1991; Járrega, 1991a). Creemos que estos términos son fácilmente traducibles al castellano como terra sigillata focense tardía, tal y como propusieron Mayet y Picon $(1986,133)$ para la lengua francesa: "sigillée phocéenne tardive» ${ }^{8}$.

\section{a) Origen y características}

Se trata de una producción tardía bastante homogénea en cuanto a formas se refiere, pero con una calidad variable con bastantes altibajos en el aspecto exterior ${ }^{9}$.

Su origen, por el hallazgo de restos de alfares junto con análisis ceramológicos, se sitúa actualmente en Focea (Mayet y Picón, 1986, 133) y un segundo alfar, subsidiario, en Grynion, localidad turca cercana a Pérgamo centro productor de menor difusión que Focea ${ }^{10}$ (Empereur y

\footnotetext{
${ }^{8}$ Los anteriores términos eran confusos y podían dar pie a errores. Por ejemplo la denominación de "Late Roman $C$ " podía confundirse con una producción antecesora de aquella, la denominada "Eastern sigillata $C$ » sigillata de Çandarli. Por ello no se debe omitir en su denominación el adjetivo de «tardía» o «tardorromana», para evitar este tipo de confusión.

${ }^{9}$ Estas diferencias en las calidades de los engobes y acabados de la $t . s . f . t$. pudo comprobarse personalmente por una de las autoras en un lote de cerámicas de Gerasa (Jarash, Jordania).

${ }^{10}$ Ninguna de las piezas focenses halladas en occidente $y$ analizadas parece pertenecer a este pequeño alfar de Grynion.
} 
Picón, 1986, 143), donde estas cerámicas se relacionan con sus antecesoras t.s. de Çandarli o t.s. oriental $C^{\prime \prime}$.

Las $t . s . f . t$. se caracterizan por un repertorio morfológico bastante reducido, unas diez formas, descritas por J. W. Hayes, que además son muy similares entre sí. En todos los casos son cuencos más o menos abiertos, por lo que una de las características de esta producción, hasta la fecha, es la ausencia de los grandes platos abiertos y la ausencia de formas cerradas. Las distintas formas diferenciadas por Hayes se basan en el aspecto de los bordes, ya que el resto de la pieza (pared, pie) es bastante similar.

Las pastas son de granulometría fina, aunque a veces se observan pequeños desgrasantes; las partículas de cal son frecuentes. En cambio, la mica es bastante rara. La pasta normalmente está bien cocida y adquiere un matiz rojo-pardusco, granate o pardo. La fractura es limpia y recta. El engobe, que cubre toda la pieza, es fino, como una película y es cohesivo con la arcilla. A veces es más espeso en el interior del cuenco y en otras ocasiones adquiere un matiz metálico. Según J. W. Hayes $(1972,232)$ este engobe es simplemente una «versión» más refinada de la arcilla.

En cuanto al acabado de las piezas, a pesar de sufrir éstas un alisado cuidado, se observan especies de finos arañazos en el exterior de las piezas. La cocción es normalmente alta, obteniéndose colores rojos, ya que se advierten bordes algo descoloridos, como el caso de la pieza de Gijón, debido a la cocción en pilas de las piezas.

J. W. Hayes realizó una importante observación sobre las técnicas de manufactura de la t.s.f.t. y era que el cuerpo y el borde se realizaban por separado (Hayes, 1972, 324), por ello la zona de unión del borde con el cuerpo es la más frágil y por donde se suelen fracturar más a menudo estas piezas.

\section{b) Forma 3E Hayes}

En Gijón sólo ha aparecido un fragmento de borde decorado a ruedecilla de la forma Hayes $3 \mathrm{E}$ (fig. 11, 8). Cronológicamente, esta forma 3 de Hayes se fecha entre la segunda mitad del siglo v d.C. y la primera mitad del siglo VI d.C. (Hayes, 1972, 337); en concreto el ejemplar gijonés es muy similar, morfológicamente, a una pieza de Corinto (Hayes, 1972, fig. 68, 15) que se fecha en el último cuarto del siglo V d.C. (VV.AA., 1981, 232).

\section{c) Difusión peninsular de la t.s.f.t.}

En cuanto a la dispersión de estas cerámicas, hasta hace pocos años sólo eran conocidas en el Mediterráneo Oriental y contados y aislados ejemplos en las islas Británicas e Irlanda, como muestra el mapa publicado por J. W. Hayes (1972, 460, Mapa 15), que sólo recogía los ejemplares peninsulares de Conímbriga. Pero en esta última década los estudios peninsulares han cambiado radicalmente este panorama (fig. 6).

1 El hallazgo de un alfar en Grynion (cercano a Pérgamo), donde se encontraron t.s.f.t. y las denominadas sigillatas de Çandarli o sigillata oriental $C$ del siglo I y II d.C., hace que actualmente se pueda afirmar algo que sólo se sospechaba por similitudes en las pastas y engobe de ambas producciones, sobre la directa derivación de la t.s.f.t. de la Çandarli. 
Las revisiones de antiguos trabajos, como el de L. Siret (1906, Lám. XXIX, 2, 3 y 4) mostraron la existencia de este tipo de hallazgos en la costa mediterránea. La mayoría de las piezas de excavaciones antiguas se englobaron erróneamente dentro de las t.s.a., caso de las del cerro de Montroy (Villaricos, Almería) (Siret, 1906), la de Águilas (Murcia) (Caballero, 1974, 207, fig. 2. 16) ${ }^{12}$ o las del Baptisterio de los Reales Alcázares de Sevilla (Bendala y Negueruela, 1980, figs. 12,15 y 13,29$)^{13}$.

Recientes hallazgos han venido a completar el panorama de la difusión de la t.s.f.t., como los de Cartagena, pertenecientes todos ellos a la forma 3, en concreto, la mayoría a la variante E de Hayes (Méndez Ortiz, 1983-84, 155; Méndez Ortiz, 1988, 144), los de Cártama (Málaga) (Serrano y Luque, 1980, fig. 17), los de Punta de l'Arenal (Jávea, Alicante) con un ejemplar de la forma $3 \mathrm{E}$, fechado entre finales del siglo $\mathrm{V}$ e inicios del vi d.C. (Bolufer, 1988, 43), los de Lucentum (Reynolds, 1987, 109) donde la forma 3E de Hayes se fecha desde finales del siglo $\mathrm{V}$ a inicios del Vı d.C., los de Rosas (Nolla-Brufau, 1984, 446) que fueron objeto de un estudio pormenorizado por parte de F. J. Nieto (1984) el cual incluyó todos los hallazgos conocidos hasta la fecha en la Península Ibérica, estudio completado por R. Járrega (1991a, 84-86) y por J. A.

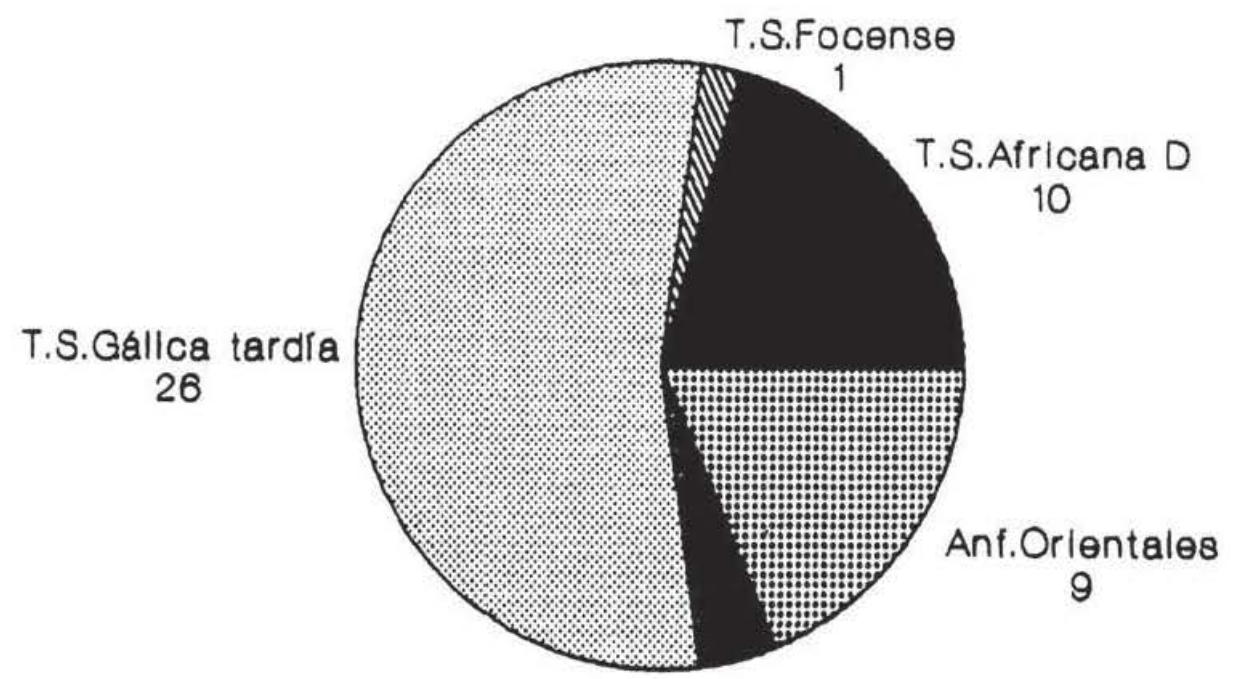

ImIt.T.S.Gálica tar

2

Figura 8.-Cerámica importada de Gijón.

12 Esta pieza fue asociada a la forma 53 de Lamboglia (forma Hayes 61B), pero L. Caballero se percató de su singularidad diciendo que se trataba de una forma nueva de t.s.a., con una decoración, también singular de ruedecilla de doble paso en el exterior del borde (Caballero, 1974, 208). Esta errónea identificación se explica fácilmente, ya que este trabajo se publicó un par de años después de la obra de J. W. Hayes, y suponemos que no era muy conocida entonces.

${ }^{13}$ La pieza fue identificada como focense por R. Járrega (1991a, 86) y J. A. Paz $(1991,223)$ aunque cada uno de estos autores sólo mencionan una pieza, el primero a la fig. 15, 29 publicada por Bendala y Negueruela (1980) y el segundo a la fig. 12, 15 de ese mismo artículo. Nosotros hemos localizado dos fragmentos de borde (Bendala y Negueruela, 1980, figs. 12, 15 y figs. 13, 29). 
Paz $(1991,223)$ donde se incluyen además los hallazgos de Caesaraugusta. Más recientemente se han publicado los ejemplares de Belo, donde la forma 3 también es la predominante dentro de las importaciones focenses, $y$ en concreto la forma $3 E$ se fecha desde finales del $\mathrm{V}$ a inicios del VI d.C. siguiendo la cronología de Hayes (Bourgeois y Mayet, 1991, 374-375).

Pero realmente los hallazgos que resultan más significativos para explicar la presencia de la t.s.f.t. en Gijón, son las piezas gallegas y portuguesas, y, en último término, las documentadas en las Islas Británicas e Irlanda.

Uno de los conjuntos más importantes es el de Conímbriga (Delgado, Mayet y Mountinho, 1975, 285-288) donde este tipo aparece fechado ya en los niveles de destrucción de mediados del $\mathrm{V}$ d.C. relacionado con la conquista sueva y donde además la forma predominante es la $\mathrm{Ha}-$ yes $3^{14}$. También están presentes cerámicas de este tipo en Braga y Tróia de Setúbal (Pereira Maia, 1977, 300). Este panorama portugués ha sido completado por Pereira Maia (1977) con nuevos hallazgos en la costa meridional portuguesa en el castro de Cacem (Sintra) con un borde de la forma 3C, en Ciudade das Rosas (Serpa), Horta de Dona María (Serpa), cerro da Vila, Loulé Velho y Marím (Pereira Maia, 1977, 301-302).

Los ejemplares gallegos, aunque escasos, se localizan en La Coruña, donde está documentada la forma 3 de Hayes (Naveiro, 1991, fig. 8, 11), la pieza del campamento de Cidadela, la de Falperra (Naveiro, 1991, 46) y el hallazgo de Noville (Murgados) correspondiente a la forma 6 de Hayes (Naveiro, 1991, 46; Pérez Losada, 1991, 91).

Importantes son los hallazgos más septentrionales, hasta ahora conocidos, $\mathrm{y}$ relacionados con un comercio marítimo. La pieza de t.s.f.t. irlandesa de Garranes (O'Riordan, 1942, 132, fig. 23, 249) se relacionó desde el primer momento de su descubrimiento con otro hallazgo británico en Tintagel. El primer hallazgo que fue relacionado con una importación oriental fue el galés de Dinas Powys (Alcock, 1964, 105-106), su descubridor señaló su similitud con otras cerámicas orientales del ágora de Atenas, Constantinópolis, Tarsus, Antioquía, Dura Europos, etc. Además la $t . s . f . t$. de Dinas Powys fue correctamente fechada después del 425 d.C. A estos hallazgos hemos de añadir los recogidos por J. W. Hayes $(1972,422)$ de Tintagel y Congresbury. Ejemplares a los que se suma el de Burdeos, en el litoral atlántico francés (Mayet y Picón, 1986, 130).

En cuanto a los hallazgos peninsulares atlánticos y cantábricos se observa que cubren toda la vía marítima desde el Mediterráneo hasta las Islas Británicas, Irlanda y litoral atlántico francés. Se confirma así la teoría emitida por J. W. Hayes, que aseguraba que la presencia de las cerámicas focenses en el sur de Irlanda y Gran Bretaña se debía a la llegada directa por mar desde el Mediterráneo, tesis que fue apoyada por otros investigadores (Mayet y Picón, 1986, 130).

En lo referente a las cronologías, al contrario de lo que ocurre con algunas de las t.s.a., parecen confirmarse las propuestas por Hayes y, su presencia en la Península Ibérica se produce desde mediados del siglo $\mathrm{V}$ d.C. a mediados del siglo vı d.C., tal y como se confirma en Iatrus (Moesia, Bulgaria), donde se presenta una de las mejores seriaciones cronológicas de la forma 3 de Hayes (Mackensen, 1991). En otros puntos del Mediterráneo, como en Cartago (Hayes, 1978,73 ) también aparecen desde mediados del siglo V d.C. a inicios del siglo VI d.C. (Hayes, $1985,40)$. En consecuencia, parece que su comercialización en Cartago no se vio afectada por la conquista vándala del norte de África.

14 Este porcentaje no es único de Conímbriga, sino que se comprueba en casi todos los yacimientos con niveles tardíos, tanto de la pars orientalis como de la pars occidentalis. 
Algunos autores han querido relacionar el auge de la presencia de las t.s.f.t. en occidente con la conquista vándala de Cartago que produciría el consiguiente descenso en la exportación de las t.s.a. (Nieto, 1984, 544-545). Esta hipótesis no parece confirmarse en el caso peninsular. Por ello la presencia de estas importaciones debemos relacionarla con la importación de otros productos, como los alimenticios, de los cuales tan sólo nos han llegado los restos anfóricos relacionados con el auge productivo de la zona oriental. Justo desde finales del IV hasta por lo menos el siglo VI d.C. se eleva el índice productivo de la agricultura de la zona microasiática.

Según Tortorella cualquier testimonio de t.s.a. $D$ asociada a $t$.s.f.t. y ánforas orientales indica las relaciones comerciales directas con Constantinópolis (Tortorella, 1986, 220).

\section{Terra sigillata gris gálica tardía}

a) Nomenclatura de las producciones gálicas tardías

La nomenclatura de estas producciones resulta un aspecto muy conflictivo. Desde la primera vez que se identificaron estas cerámicas y hasta estos últimos años han sido numerosas las denominaciones por las que han sido conocidas. A principios de este siglo fueron publicadas con el adjetivo de «visigodas» por J. Déchelette (Déchelette, 1904; Rigoir, 1968, 177), término que fue desechado por J. Rigoir, ya que esta producción, cronológicamente, se situaba por lo menos cuarto de siglo antes de la llegada de los visigodos. Cazurro (1909-1910) optó por esta misma denominación para los hallazgos peninsulares.

Un término más general, pero también vago es el adoptado por H. Zeiss (1933) de cerámicas de la antigüedad tardía ("spätantiken Keramik»). Años más tarde se impuso la denominación de «cerámica estampada» que supuso aún mayores problemas, ya que englobaba no sólo a las producciones gálicas tardías, sino también a las africanas (Palol, 1948, 466-468).

Desde finales de la década de los años sesenta y tras la publicación del trabajo de carácter tipológico de J. Rigoir (1968) estas cerámicas son conocidas con el nombre de t.s. paleocristianas grises y anaranjadas.

Uno de los mayores problemas que afectan a estas producciones en España, reside en el hecho de que han sido estudiadas por su decoración estampada y no por su origen; como ya hemos indicado bajo la denominación de «estampadas» romano-cristianas (Palol, 1948) se incluyó tanto las producciones gálicas como las africanas y las hispánicas. Con la designación de "cerámica tardorromana-visigoda anaranjada y gris con decoración estampada" (Mañanes, 1980) ocurrió algo similar, aunque en esta última obra se desglosan las producciones africanas (Mañanes, 1980, 218); lo mismo sucede con la llamada «cerámica romano-visigoda con decoración estampada» de Romero Carnicero (1974). L. Caballero (1972) mantuvo la denominación francesa llamando a estas producciones «sigillata gris anaranjada paleocristiana», y siguiendo a Rigoir hace claras referencias a los alfares gálicos.

El panorama de la nomenclatura se complicó algo más cuando J. e Y. Rigoir (1971) rebautizaron sus producciones paleocristianas fabricadas en la Galia y las llamaron «dérivées des sigillées paléochrétiennes». Este nuevo nombre hizo que se complicasen aún más las cosas, ya que por ejemplo L. Caballero por su parte decidió mantener la denominación original de los autores franceses. Por último cabría mencionar la postura adoptada por F. Mayet $(1984,268)$; esta in- 

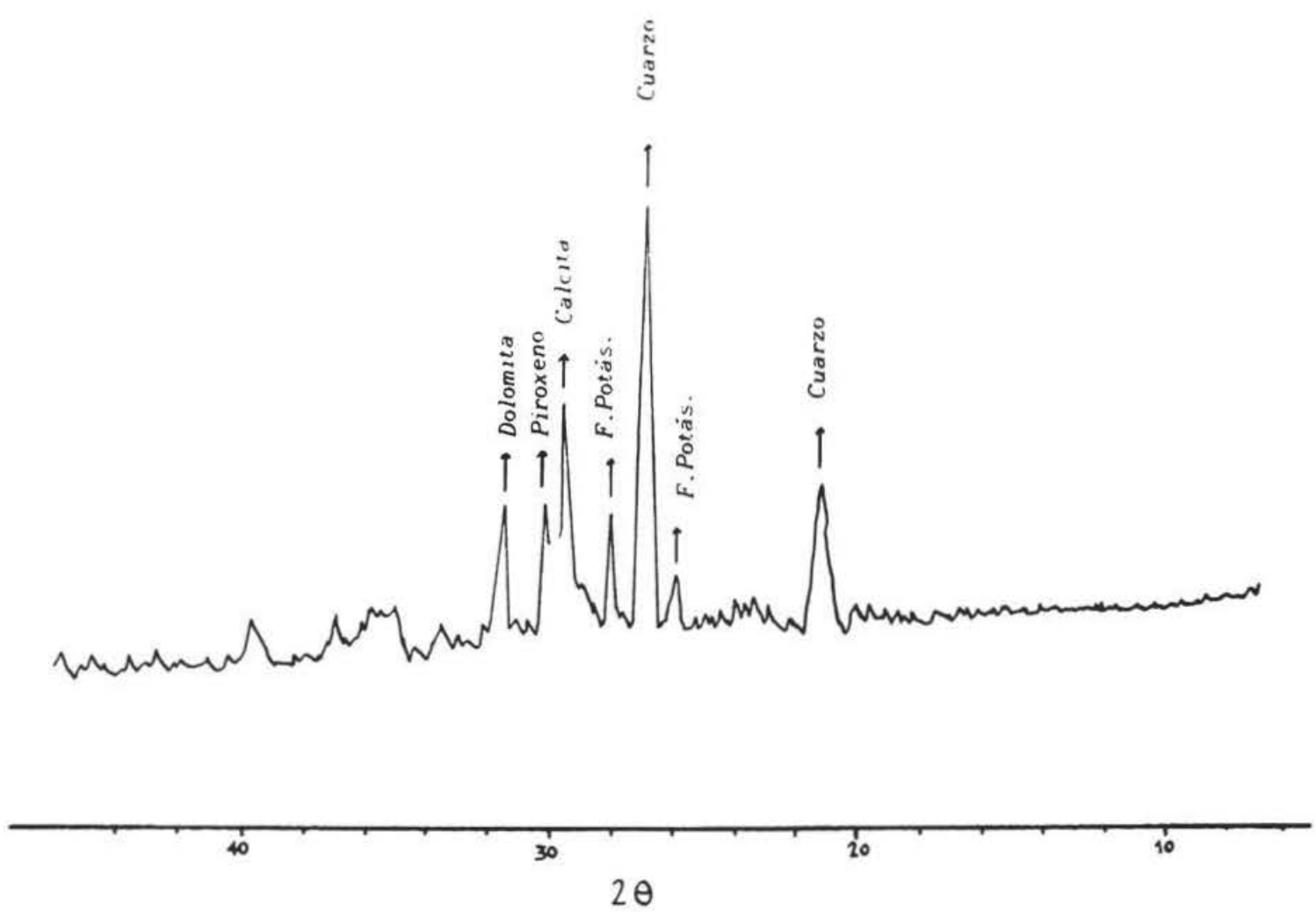

Figura 9.-Difracción de Rayos X de dos ánforas tardorromanas.

vestigadora, optó por denominar a estas producciones como sigillatas tardías de Galia, que es la que nosotros adoptamos en este trabajo por parecernos la más adecuada, aunque queda claro que estas producciones no son sigillatas propiamente dichas (Rigoir, 1968, 179) y que este término se acepta de forma convencional, como en el caso de las africanas, focenses o chipriotas.

Por contra, pensamos que el término de estampada debe desecharse. Como hemos visto, conlleva numerosos problemas, ya que engloba a distintas cerámicas contemporáneas fabricadas en diversos centros productores, como las t.s.a., las t.s. hispánicas tardías decoradas con estampilla junto con las gálicas propiamente dichas. Además la denominación de estampada resulta equívoca, como señaló J. Rigoir $(1968,179)$ los términos de sigillata y estampada son etimológicamente equivalentes. Por otro lado, esta cerámica tardía no sólo se decora con estampillas, sino que también aparece adornada con ruedecilla e incluso existen formas lisas.

El término de derivadas propuesto por J. e Y. Rigoir en el caso peninsular resulta confuso. En concreto, en la zona que aquí estudiamos existen una serie de producciones hispánicas que ya se han denominado de imitación de paleocristianas (Carrocera y Requejo, 1989, 16).

El adjetivo de Paleocristianas, que aunque para L. Caballero $(1972,205)$ resulte más aceptable que el de visigodas, es demasiado concreto y puede resultar equívoco, como señala F. Mayet $(1984,268)$. Hace referencia a unos tipos de estampillas muy concretos, de carácter cristiano (Bolufer, 1988, 42) y el repertorio iconográfico-decorativo de estas cerámicas no sólo se reduce a estampillas cristianas. 
En resumen. nos parece más correcto hablar de terras sigillatas grises gálicas tardías, tal y como propuso F. Mayet $(1984,268)$.

b) Características y centros de producción de la terra sigillata gris gálica tardía

J. Rigoir (1968, 181-183) estableció tres centros de producción 15:

1. Grupo Narbonense o del Languedoc.

2. Grupo Provenzal.

3. Grupo Atlántico con centro en Burdeos.

Al último grupo, atlántico, es al que pertenecen las piezas de Gijón. Este grupo se caracteriza por tener la producción más homogénea de todas las gálicas tardías, aunque en cuanto a formas, su repertorio es limitado. Las pastas están compuestas por unas arcillas finas, casi sin desgrasantes a simple vista, aunque a veces tienen inclusiones de pirita, calcita o cuarzo (Rigoir y Meffre, 1973, 207), no se puede decir que sean homogéneas ya que las pastas suelen variar en su aspecto ligeramente. El engobe suele ser brillante, de tonalidad oscura, generalmente bien adherido a la pasta y adquiere un tacto jabonoso por pulido (Rigoir, 1968, 185). La cocción del taller atlántico es predominantemente reductora y casi no hay producciones anaranjadas (Rigoir, 1968, 182, Mapa 4).

Las formas atlánticas son menos variadas que las de las producciones del Languedoc o la Provenza, suelen presentar perfiles más pesados o gruesos que aquéllas. Destaca la total ausencia de las formas 2 y 8 de Rigoir; las formas 3, 13, 14, 15, 18 y 22 son bastante raras o escasas (Rigoir y Meffre, 1973, 222) y predominan las formas 1, 4, 6 y 16 (Rigoir y Meffre, 1973, fig. 7). Todas se realizan a torno.

En cuanto a la decoración podemos decir que la dominante, con respecto a las otras dos producciones francesas, es la impresa a ruedecilla. Las estampillas también están presentes, sobre todo las de carácter cristiano. J. Rigoir $(1968,185)$ señaló en su día la marcada intención religiosa de las estampillas atlánticas. Tienen un trazo curvilíneo. Uno de los punzones más representativos es el de un cérvido, de tamaño mayor que los ciervos narbonenses o provenzales, y suele ir acompañado por otros motivos: palmas, cruces, estrellas, soles y otros animales, incluso esquemáticas representaciones humanas.

La cronología de toda la producción gálica tardía es bastante imprecisa, aunque parece que los talleres atlánticos son algo más tardíos. La fecha más antigua de toda la producción es la primera mitad del siglo IV d.C. cuando aparecen en el Languedoc (Caballero, 1972, 206; Mayet, 1984; Palol, 1948, 459; Rigoir, 1968, 187) y las piezas más tardías aparecen asociadas a enterramientos merovingios del siglo VII d.C. La fecha de inicio de esta producción se fijó en el siglo IV d.C. porque muchas de estas cerámicas aparecían asociadas a monedas del siglo IV d.C. La asociación de estas cerámicas a las pequeñas monedas del IV d.C. resulta problemática, ya que estos bronces (AE3 y AE4) se pueden fechar sin ningún problema en el siglo V d.C. (Mayet, 1984, 268) tal y como ocurre en Cartago (Hayes, 1977, 280). Para la datación de las t.s.g.g.t.

is Las producciones de los talleres de la Narbonense y Provenza son ampliamente estudiados por J. e Y. Rigoir (1968, 1971 y 1981) por lo que nos remitimos a estos trabajos ya que las piezas de Gijón son del grupo Atlántico o Aquitano. 
J. Rigoir empleó el modelo estratigráfico del oppidum de Saint-Blaise (bocas del Ródano). En este yacimiento las t.s.g.g.t. aparecían junto con otras producciones como lucentes, t.s. claras $B$ y las t.s.a. D. Las hipótesis de J. Rigoir se basaron en la observación del paulatino aumento de las $t . s . g . t$. con respecto a las otras producciones en los distintos niveles analizados (Rigoir, 1968, 190-191).

En España parece que las piezas de los talleres del Languedoc y Provenza se documentan en el valle del Ebro a mediados de la segunda mitad del siglo IV d.C. (Paz, 1991, 209).

Uno de los problemas que presenta el estudio de estas producciones es que, al contrario de las formas de $t . s . a$., la tipología de las gálicas definida por Rigoir, por el momento, no tiene connotaciones cronológicas, es decir, que se trata simplemente de una clasificación morfológica.

La dispersión de la producción atlántica es fundamentalmente francesa y se sitúa entre los valles del Loira y el Garona (Rigoir y Meffre, 1973, 207). Fuera de esta zona sólo se documentan en el yacimiento galés de Dinas Powys.

\section{c) Producciones atlánticas en Gijón}

El conjunto de Gijón resulta un hallazgo importante ya que, hasta la fecha, en la Península Ibérica sólo se conocían las producciones gálicas de los talleres del Languedoc y la Provenza francesa ${ }^{16}$. J. A. Paz $(1991,208)$ señala, no obstante, el posible origen atlántico de un plato de Clunia (Rigoir, 1971, 36-37) y otro de Ampurias (fig. 7). En el fondeadero de cabo Higuer (Hondarribia, San Sebastián) se menciona la existencia de t.s.g.g.t. aunque no se determina la procedencia de las mismas tal vez provengan del taller aquitano, dada la relación comercial existente entre esta costa española y Burdeos (Benito, 1988, 158-159). Los productos atlánticos constituyen uno de los grupos mejor representados en el conjunto de las Termas de CimadeviIla. En las excavaciones de principios de siglo, C. Alvargonzále $z^{17}$ dibujó una pieza fácilmente identificable con los hallazgos que hemos realizado recientemente y que damos a conocer en el presente artículo.

\section{Forma 1 Rigoir}

Con esta forma, que es una de las mejor representadas en el grupo atlántico, hemos identificado dos fragmentos (fig. 12,13-14); ambos están decorados en el borde con motivo impreso a ruedecilla, motivo típico del repertorio atlántico. Esta forma se utilizó como fuente (Rigoir y Meffre, 1973, 223). Ejemplares similares se localizan en Burdeos (Rigoir y Meffre, 1973, PI. I, 2826 y 4384), en Saint Bertrand de Comminges (Alto Garona) (Rigoir y Meffre, 1973, Pl. I,

\footnotetext{
16 Esta idea estaba muy extendida: «...cette production (atlántica) ne traverse absolument pas les $P$ y. rénnes; même sur les côtes atlantiques, espagnoles ou portugaises, elle n'a encore jamais étè signalée dans acun site» (Rigoir, 1971, 38).

17 C. Alvargonzález define esta producción como: «Fragmento de una taza de harro gris azulado, cubierto de un barniz negro muy similar a las de Faro. En el Museo de Nápoles existen ejemplares de estos barros negros clasificados como "pasta locali" ".
} 
3708), en Ardenos (cerca de Burdeos) (Rigoir y Meffre, 1973, PI. I, 3694), en Poitiers (Rigoir y Meffre, 1973. PI. I, 3344) y en Nantes (Rigoir y Meffre, 1973, Pl. I, 2927).

En Murias de Paraxuga, en Asturias, hay un plato asociable a esta forma, pero realizado en un alfar hispánico (Carrocera y Requejo, 1989, 27, fig. 1, 10) fechado entre finales del siglo IV y siglo $v$ d.C. También hay ejemplares en Villanueva de Azoague (Zamora) realizados en un posible alfar local (López y Regueras, 1987, 138).

En la Península Ibérica esta forma fabricada en los talleres provenzales y languedocienses se fecha de manera general desde el último cuarto del siglo IV d.C. (Paz, 1991, 211). En el vertedero de Tarragona, una pieza provenzal se data en el segundo cuarto del siglo V d.C. (VV.AA., 1989, 167). También existen ejemplares en Monte Cildá (Olleros del Pisuerga, Palencia) (Caballero, 1974, 212) o en Valencia (Reynolds, 1984, 533, figs. 18-24, n." 462). Como nuestras piezas son las únicas que pertenecen a la producción atlántica, y ésta es algo más tardía que la languedociense o la provenzal, debemos recortar algo esta cronología y llevarla a mediados del $\mathrm{v}$ d.C. o inicios del vı d.C.

\section{Forma 4 Rigoir}

Este plato es, al parecer, una de las piezas que más se fabricó en los talleres atlánticos. Según J. Rigoir se inspira en la forma 9 de Lamboglia de $t$.s. clara $B$ (Rigoir, 1968, 202), producida en la Narbonense.

En Gijón están presentes las dos versiones que tiene esta forma. Una lisa, conocida desde antiguo, ya que fue publicada por primera vez por C. Alvargonzález (1965, 59, Lám. XIX, fig. 9) que reproducimos aquí (fig. 17, 43) ${ }^{18}$ y un nuevo hallazgo (fig. 12,15). En Francia también hay paralelos de esta versión lisa, como los de Saint Bertrand de Comminges (Rigoir y Meffre, 1973, PI. V, 3755 y 3783).

Existe una versión caracterizada por una o varias acanaladuras horizontales en el exterior de estos platos (fig. 13,16). De la versión con dos o varias acanaladuras en el exterior hay ejemplos franceses, como los de Burdeos (Rigoir y Meffre, 1973, PI. V, 2763 y 2815) o el de Saint Bertrand de Comminges (Rigoir y Meffre, 1973, PI. V, 3712). En Asturias también se localiza una forma similar, aunque definida como t.s. hispánica tardía imitación paléocristiana (Carrocera y Requejo, 1989, 26), de Murias de Paraxuga (Carrocera y Requejo, 1989, fig. 1, $10)^{19}$.

\footnotetext{
18 Esta pieza no fue tenida en cuenta en la revisión de Maya de 1977.

19 En Murias de Paraxuga se hallaron dos piezas asociadas a las formas 1 y 4 de Rigoir. Ambas piezas se englobaron dentro de la misma denominación de t.s. hispánica tardía imitación paleocristiana del grupo antiguo de L. Caballero (Carrocera y Requejo, 1989, 27): nosotros propondríamos considerarlas dos ejemplares de origen distinto pues como pudimos comprobar durante una visita al Museo de Oviedo donde se exhiben estas piezas, pertenecen a dos producciones claramente diferenciadas, ya que la forma 4 de Rigoir es muy similar a las de Gijón, con decoración de ruedecilla incluso y, por tanto, susceptible de ser considerada como una importación atlántica y la segunda, forma 1 de Rigoir (Carrocera y Requejo, 1989, fig. 1, 14), sí correspondería a una producción local o regional inspirada en las t.s.g.g.t. importadas.
} 

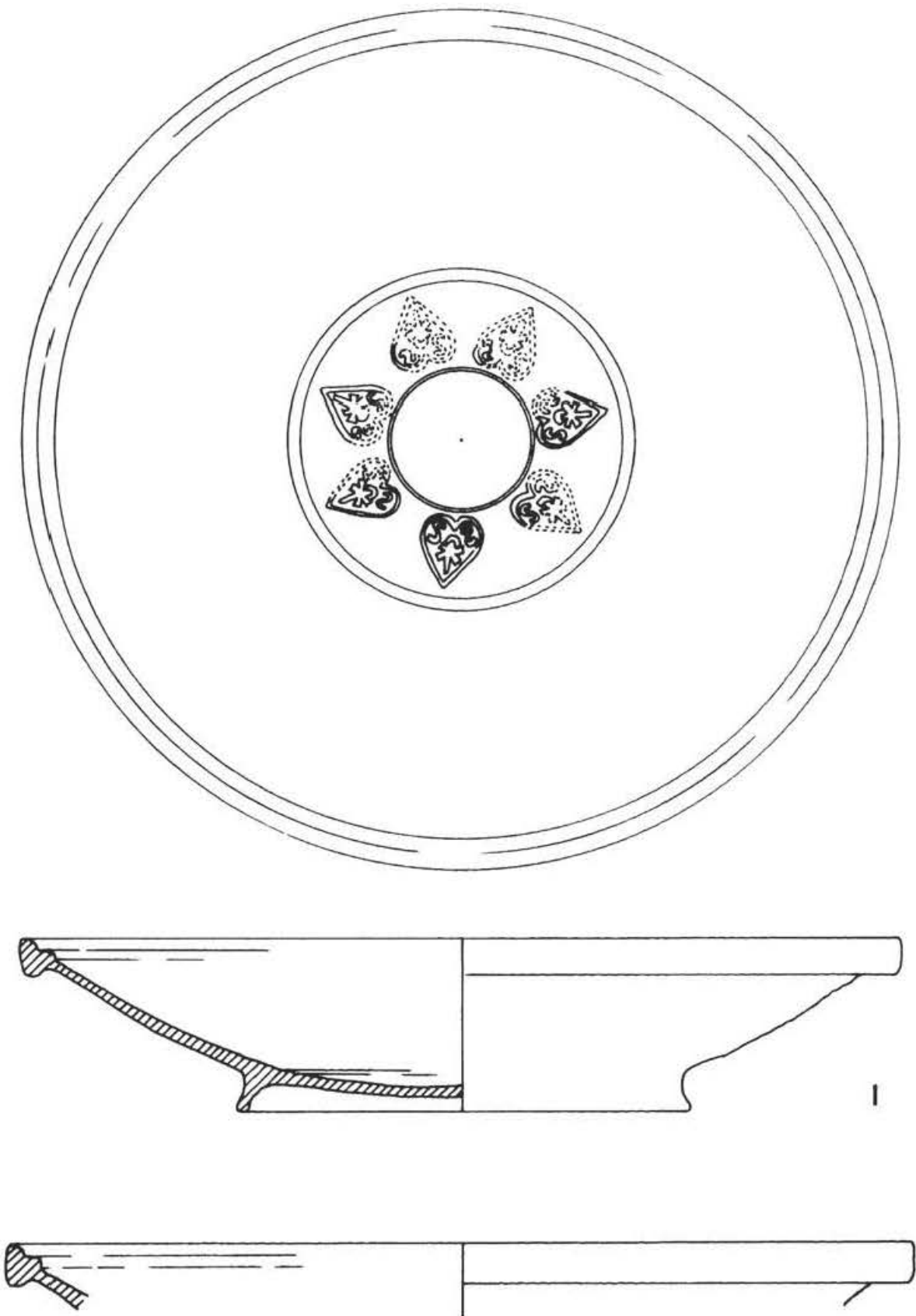

Figura 10.-Terra Sigillata Africana D. 1 y 2 forma 104 Hayes variante Gijón. 
Forma 16 Rigoir

Este cuenco carenado (Rigoir, 1968, 205) es la forma mejor representada en Gijón, aunque en el taller atlántico no es tan abundante como las formas 1 y 4 . La forma 16 es más frecuente en las producciones provenzal y narbonense (Rigoir y Meffre, 1973, 224). Al parecer es la forma más importada, ya que contamos con ejemplares en Gales, en el yacimiento de Dinas Powys. Pero la mayoría de los paralelos de esta forma son franceses, como los de Poitiers (Rigoir y Meffre, 1973, Pl. XV, 2800 y 2801) y Ardenos (Rigoir y Meffre, 1973, Pl. XV, 3736).

La ruedecilla es el motivo más extendido en los cuencos de la forma 16, tal y como se comprueba con el lote de Gijón (figs. 13, 17-19). Existe un motivo a ruedecilla (fig. 13, 18), que a pesar del mal estado de conservación en el que se encontró la pieza ${ }^{20}$ podemos decir que es similar al tercer tipo de ruedecilla observado por Rigoir y Meffre $(1973,244)$, definido como múltiples depresiones que no fueron producidas por una sóla ruedecilla (Rigoir y Meffre, 1973, fig. 11, 3699); resulta una técnica indeterminada, pero su existencia en Gijón viene a afirmar la hipótesis del directo aprovisionamiento de esta ciudad de los alfares del litoral atlántico francés.

\section{Forma 18 Rigoir}

Según J. Rigoir $(1968,207)$ esta forma deriva de las t.s. sud-gálicas (forma 37 Drag.) a través de la forma 2 de $t$.s. clara $B$ y la forma $2 / 37$ de la lucente y es una de las formas más características de esta producción gálica tardía. En Zaragoza, dentro de la producción languedociense se fecha en un nivel de finales del siglo V d.C. o principios del VI d.C. (Paz, 1991, 218). En Gijón tenemos un pequeño fragmento (fig. 14, 20) que pudiera pertenecer a esta forma. Es similar pero no igual a los publicados por Rigoir, por lo que esta clasificación no es de ningún modo segura y tiene para nosotros un carácter preliminar.

\section{Bases decoradas de terra sigillata gris gálica tardía}

En primer lugar tenemos una base decorada con varios punzones (figs. 14, 26 y 18, 26). Su decoración está compuesta por un motivo central formado por un ciervo, rodeado por series de palmetas y rosetas, todo ello dispuesto en el interior de la pieza y rodeado por un círculo impreso a ruedecilla. El motivo central de cérvidos es muy corriente en la producción atlántica ${ }^{21}$ y sólo aparece esporádicamente en las otras producciones gálicas (Rigoir y Meffre, 1973, 248); suele aparecer asociado a otros motivos secundarios como ruedas, estrellas, etc., pero su significado es enigmático (Rigoir, 1981, 182). Los punzones que rodean a esta estampilla central son una palmeta (Rigoir y Meffre, 1973, Pl. XXI, 2175) y una roseta (Rigoir y Meffre, 1973, Pl. XIX, 2529).

${ }^{20} \mathrm{El}$ engobe de este ejemplar se halla totalmente perdido y el exterior, e incluso la superficie de la pieza parece alterada, pero no lo suficiente como para no apreciar este tipo de ruedecilla impresa.

${ }^{21}$ Dentro del repertorio de Rigoir no hemos hallado ninguna estampilla idéntica a la de Gijón, sólo similares. 

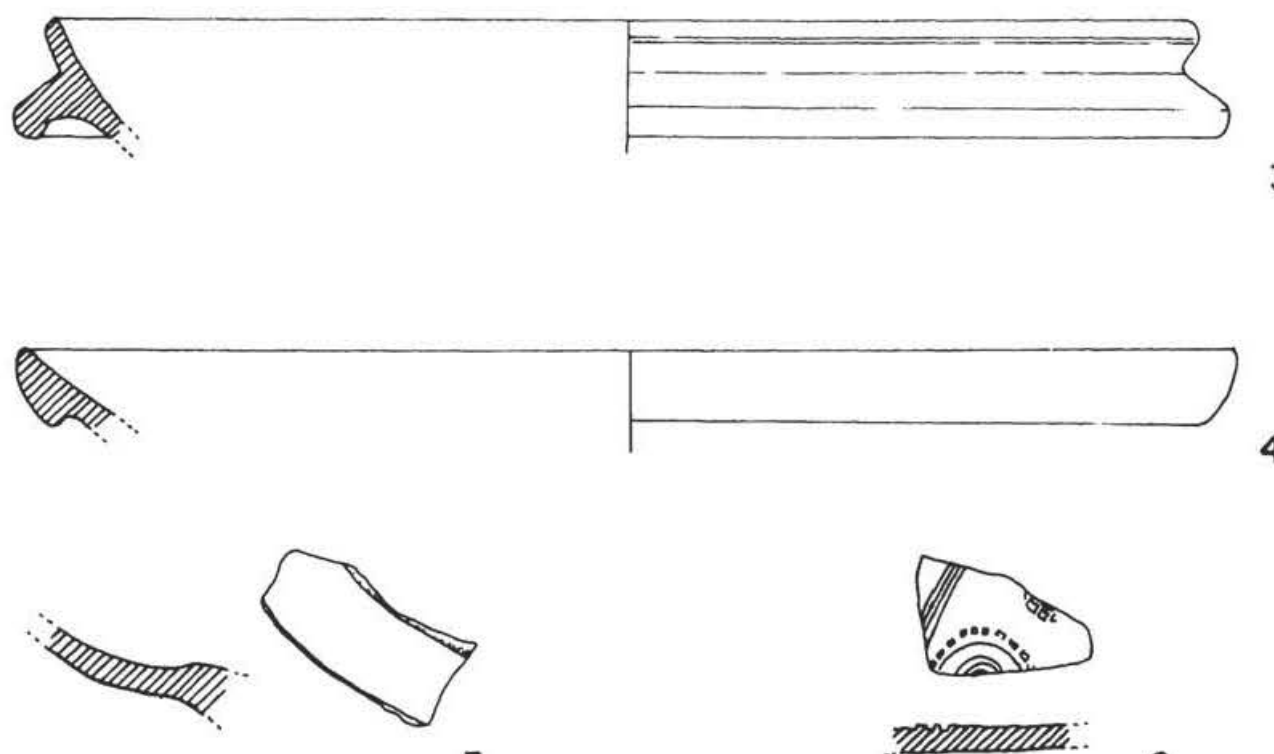

5

6
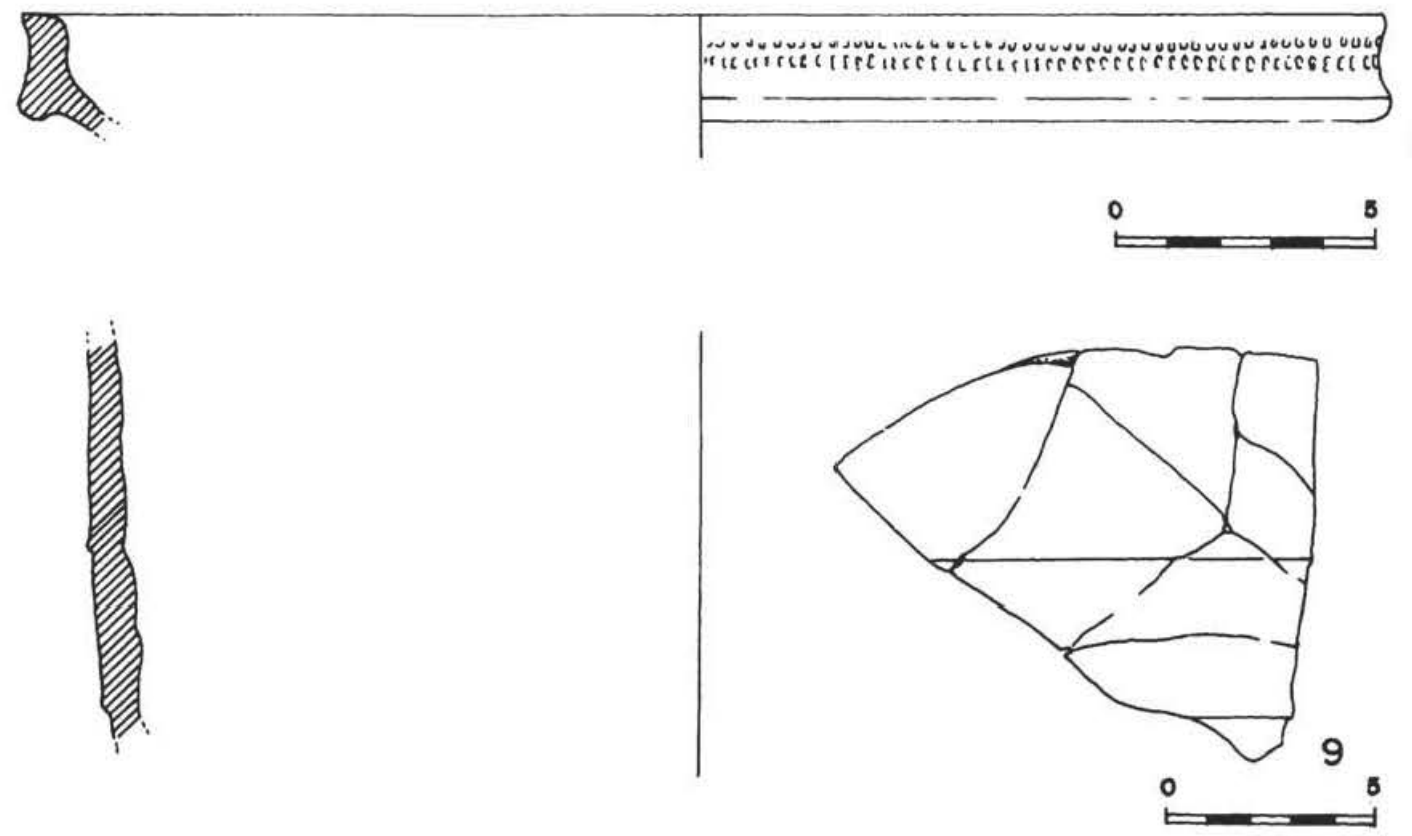

Figura 11.-Terra Sigillata Africana D (3, forma 91C Hayes, 4, forma 99 Hayes, 5, base indeterminada, 6, estampilla estilo A (ii) Hayes. Terra Sigillata focense tardía (8, forma 3E Hayes). Anfora Tardorromana Tipo 1 de Cartago (9). 
El resto son bases decoradas a ruedecilla (figs. 14, 21-22 y 15, 27-29) que pudieron pertenecer tanto a la forma 1 como a la 4 de Rigoir. Incluso hay un ejemplar que muestra restos de una estampilla (fig. 15,29), y una base con pie alto perteneciente a la forma 16 ó 18 de Rigoir (fig. 15, 34).

No tenemos muchos datos en Gijón para fechar estas formas de t.s.g.g.t., pero podrían situarse, al igual que las otras importaciones halladas en las Termas del Campo Valdés en un horizonte de finales del siglo $\mathrm{V}$ d.C. y primera mitad del VI d.C.

\section{Imitaciones de terras sigillatas grises gálicas tardías (talleres locales o regionales)}

El estudio de este tipo de producciones está aún en sus inicios. Caballero y Argente (1975, 142 ) intuyeron la existencia de una imitación de la cerámica paleocristiana ${ }^{22}$ al documentar una serie de estampillas que no coincidían con las clásicas publicadas por Rigoir.

Se tienen noticias de la existencia de algunos talleres hispánicos cuyas formas y decoraciones recuerdan a las t.s.g.t., tanto en su versión gris como anaranjada. En concreto hay bastantes indicios en Villanueva de Azoague (Zamora) para pensar en una producción local influenciada por las t.s.g.g.t. (López y Regueras, 1987, 138) y en Nájera (Garabito, 1983, 189) fechados en los siglos IV y $\vee$ d.C. En el Cantábrico, también se han localizado producciones de este tipo, aunque a diferencia de las zamoranas de Azoague, las formas abarcan platos y en mayor medida cuencos. Estas producciones cantábricas se relacionan con las cerámicas tardorromanas de la Meseta y Noroeste peninsular y para E. Carrocera y O. Requejo $(1989,16)$ son una manufactura de carácter local o regional que imitan o están influidas por los talleres gálicos contemporáneos, serían las producciones que L. Caballero denomina t.s. hispánica tardía de imitación paleocristiana.

El grupo de producciones de «imitación paleocristiana» asturiano que estudian Carrocera y Requejo (1989) procede de los yacimientos de Murias de Beloño, Murias de Paraxuga, Castro de Coaña y Castro de Pendia. Este grupo se caracterizaría por unas pastas finas y de buena calidad de color grisáceo, un engobe gris oscuro o negro, cocciones reductoras, y sus formas y decoraciones estarían influenciadas por los productos gálicos, fechándose de forma general desde finales del IV d.C. y durante el v d.C. (Carrocera y Requejo, 1989, 27).

Sin embargo, el lote de Gijón no se parece al definido por estos autores, ni por características de las pastas ni siquiera en las formas. Lo único que une las imitaciones de Gijón al resto de las imitaciones asturianas es su inspiración en ciertas formas de cerámicas importadas. El grupo gijonés está formado por tres piezas pertenecientes a una misma forma (figs. 16, 3840). La pasta de estos cuencos se podría considerar casi del tipo común, aunque lo suficientemente distinta, por aspecto y acabado, de las cerámicas comunes locales halladas en las excavaciones de las Termas, como para ser considerada como importación. Carecen absolutamen-

${ }^{22}$ "A pesar de esta indeterminación, no debemos dudar, en ningún modo, en la existencia de una importación de cerámica paleocristiana del sur de Francia, que penetra hasta el interior de la Península; en la existencia de una producción de cerámica paleocristiana española y en la de imitaciones más locales, por tanto, también realizadas en España, de las producciones anteriores, bien de formas, bien de decoración.... (Caballero y Argente, 1975, 142).

${ }^{23}$ Estos cuencos jamás estuvieron cubiertos por ningún tipo de engobe; al contrario de otras muchas 
te de engobe ${ }^{23}$ y fueron cocidas en una atmosfera reductora irregular, tras la cual adquirieron tonalidades grisáceas y en ocasiones, en la superficie de las piezas, se observan zonas de color ocre.

Dos de los ejemplares tienen decoración en el borde, una muy simple, realizada con un punzón fino de sección cuadrangular (fig. 16, 39) y otra con series de «especie» de cruces (fig. 16, 38) siempre dispuestas en la parte superior del borde. De este último motivo de «cruz» o aspas cruzadas con un pequeño círculo central tenemos un punzón similar en un cuenco anaranjado del castro de Monte Cildá (Olleros del Pisuerga, Palencia) (Bohigas y Ruiz, 1989, 42, figs. 5 , 10 y 11). La Pieza de Monte Cildá, fechada en el siglo V d.C. estaría relacionada con las denominadas t.s. de imitación gálicas tardías. Se documenta un motivo semejante en el alfar tardío de Nájera (Garabito, 1983, fig. 4).

En cuanto a la forma, el prototipo de este cuenco de borde poligonal, en estrella o «festonea-do" ( "scalloped rim»), lo encontramos en la forma de t.s.a. D 97 de Hayes, fechada en Cartago entre finales del siglo V d.C. e inicios del VI d.C. (Hayes, 1976, 56), aunque la forma general se fecha del 490 al 550 d.C. (Hayes, 1972, 151). En la Península Ibérica está atestiguada la presencia de cuencos africanos de la forma 97 Hayes, en Mérida (Vázquez, 1985, 61), en Belo (Bourgeois y Mayet, 1991, 305) y en Conímbriga, por ejemplo, donde aparecen los primeros ejemplares datados en la primera mitad del siglo V d.C. (Bourgeois y Mayet, 1991, 306).

También en las t.s.g.g.t. encontramos otro prototipo similar, en la forma 3 b de Rigoir (Rigoir, 1968, 202) que está ausente de la producción atlántica. Por tanto, nuestros ejemplares, de confirmarse su vinculación con las t.s.g.g.t., deben relacionarse con los talleres languedocienses o provenzales. En Tarraco existen ejemplares importados de la forma 3 b de Rigoir (VV.AA., 1989, 158-159, figs. 68, 2.8) fechables en el segundo cuarto del siglo V d.C. (VV.AA., 1989, 167).

Por el momento y ante los datos aportados aquí, debemos contentarnos con clasificar estos tres cuencos de borde poligonal de Gijón dentro de la gran familia de "imitaciones de t.s.g.g.t.», sin que sepamos el lugar de origen de estas producciones. Su cronología, a modo de hipótesis debería de situarse entre los siglos $v$ y primera mitad del VI d.C.

\section{5. Ánforas orientales}

\section{a) Nomenclatura}

Este tipo de importación anfórica ha sido identificada e integrada dentro de diferentes tipologías locales en distintos yacimientos durante los últimos veinte años. Por ello creemos imprescindible indicar la serie de nomenclaturas con las cuales son conocidas estas producciones: Tipo Británico ii, tipo Ballana 6, ánfora tardorromana tipo 1 de Cartago ("Carthage Late Roman Amphora I»), Beltrán 82, Scorpan 8B, Keay LIII (Keay, 1984, fig. 32), Yassi Ada 1, Clase 44 de Peacock y Williams $(1986,185)$ y Kuzmanov XIII.

piezas de t.s.g.g.t. o de t.s. hispánica, que debido a las condiciones ácidas del suelo de Cimadevilla lo han perdido, adquiriendo muchas piezas, por esta degradación, una textura talcosa. 


\section{b) Origen y contenido}

La primera vez que se localizó este tipo de ánforas fue en Gran Bretaña, y Thomas (1959) pensó que su origen estaba en las islas griegas. Otros investigadores, como Lang pusieron su origen en Chipre (Williams, 1982, 103). J. W. Hayes y J. A. Riley propusieron, en un principio, una procedencia egipcia, concretamente en Memphis (Riley, 1976, 117). Años más tarde Riley negaría este origen (Riley, 1982, 116). Algunos autores basándose en hipótesis sobre el contenido de los recipientes pensaron que el norte de África sería la zona originaria de estas ánforas, pero tras los análisis de pastas que se realizaron, esta zona quedó descartada, pues los resultados de estos análisis apuntaban hacia una zona que tuviera abundancia de rocas ultrabásicas de origen volcánico (Williams, 1982, 103), concretamente, la zona de Antioquía. Los resultados de los análisis de D. F. Williams (1982) de minerales pesados son bastante similares a los obtenidos en la Universidad Autónoma de Madrid y explicados en el anexo de este mismo artículo (cfr. infra) ${ }^{24}$.

Actualmente no hay ningún problema en admitir su origen en la región de Antioquía del Orontes (Fulford y Peacock, 1984, 200) o norte de Siria (Peacock y Williams, 1986, 187). Aunque para otros autores, la variedad detectada en sus pastas sugiere más de un centro de producción (Keay, 1984, 271) ${ }^{25}$.

En cuanto a su contenido, si fue el aceite, pudieron producirse en Antioquía entre inicios del siglo $V$ y mediados del VII d.C. (Peacock y Williams, 1986, 187). En una pieza catalana (Keay, 1984, T/6/493) se hallaron restos de resina. Ciertamente en La Bourse (Marsella) se observaron restos no oleaginosos en un ánfora de este tipo, pero en su versión más antigua (Bonifay, 1986, 300-301). Para C. Panella su contenido aún está por determinar, pudo ser tanto vino como aceite (Panella, 1986, 270).

\section{c) Características}

En Gijón no tenemos ninguna forma completa, tan sólo fragmentos de paredes, caracterizados por su perfil «escalonado» (fig. 11, 9) y fragmentos de asas (fig. 12, 12).

Las pastas son de colores claros, cuero (Riley, 1982,116), ocre-amarillento o anaranjado claro (Cailleux L 53, L 70, L 75, M 69 ó M 77), con desgrasantes de color negro, calcita y cuarzo (cfr. anexo).

Este ánfora se caracteriza por un cuerpo más o menos abolsado con un perfil «escalonado», base redondeada, cuello y hombros marcados y borde redondeado con una ligera carena en el labio exterior, y dos asas de sección oval con una o dos acanaladuras longitudinales que arran-

\footnotetext{
${ }^{24}$ Los análisis de minerales pesados y difracción de Rayos X realizados con dos muestras de ánforas de este tipo procedentes de las excavaciones de las Termas del Campo Valdés (Cimadevilla, Gijón) por la doctora doña Rosario García Jiménez, del Departamento de Química Agrícola y Geoquímica de la Universidad Autónoma de Madrid, han dado resultados similares a los publicados por D. F. Williams (1982), por lo que a su aspecto exterior unimos la similar composición minerealógica para afirmar que los fragmentos de Gijón fueron importados desde Asia Menor y posiblemente de la zona de Antioquía, ya que pertenecen al ánfora tardorromana tipo 1 de Cartago, originaria de esa zona.

${ }_{25}$ Esta aparente variedad en las pastas simplemente puede deberse a un factor cronológico, no hay que olvidar que estas ánforas se produjeron durante más de dos siglos, desde el IV al VII d.C. por lo menos.
} 

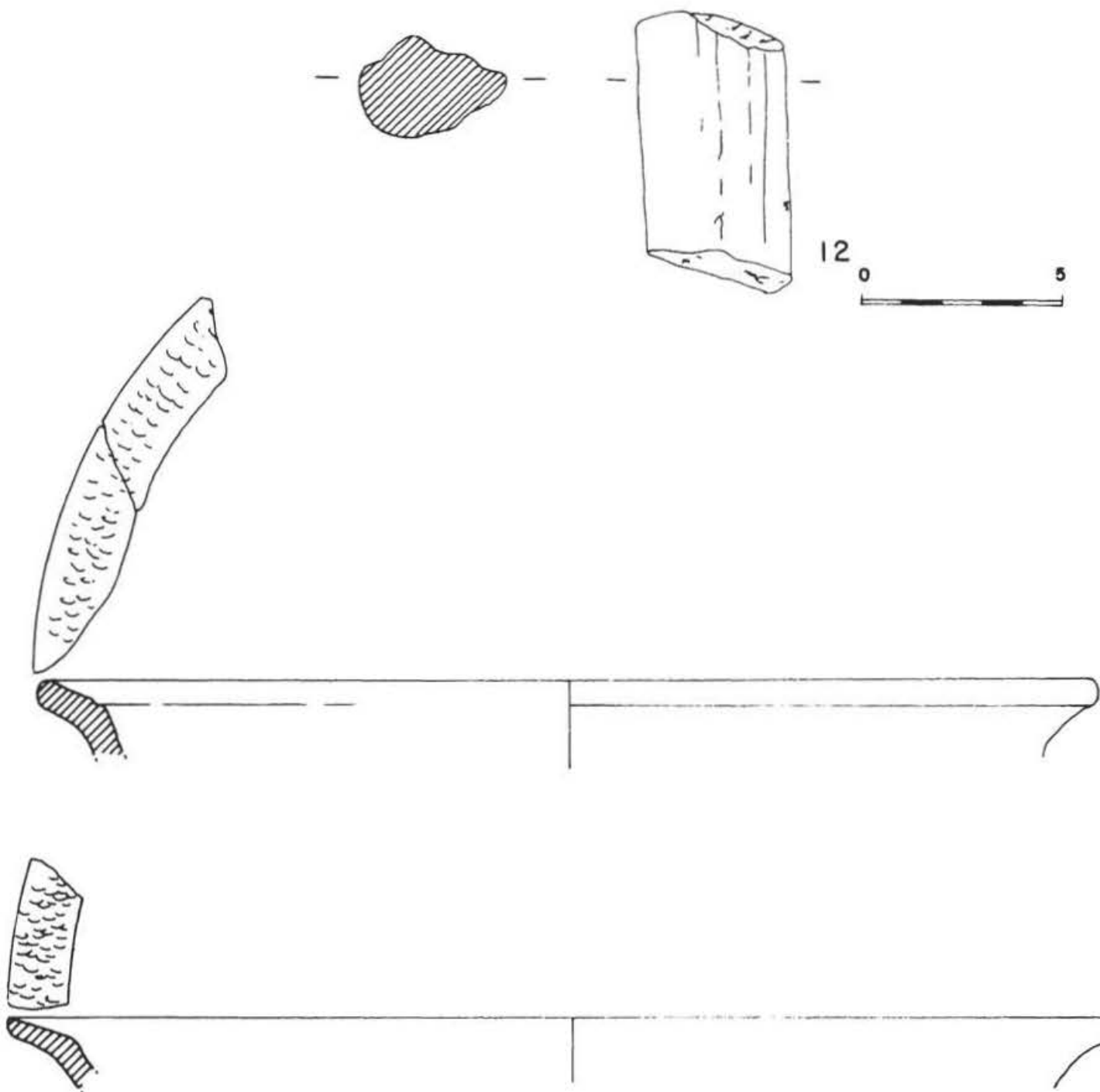

0
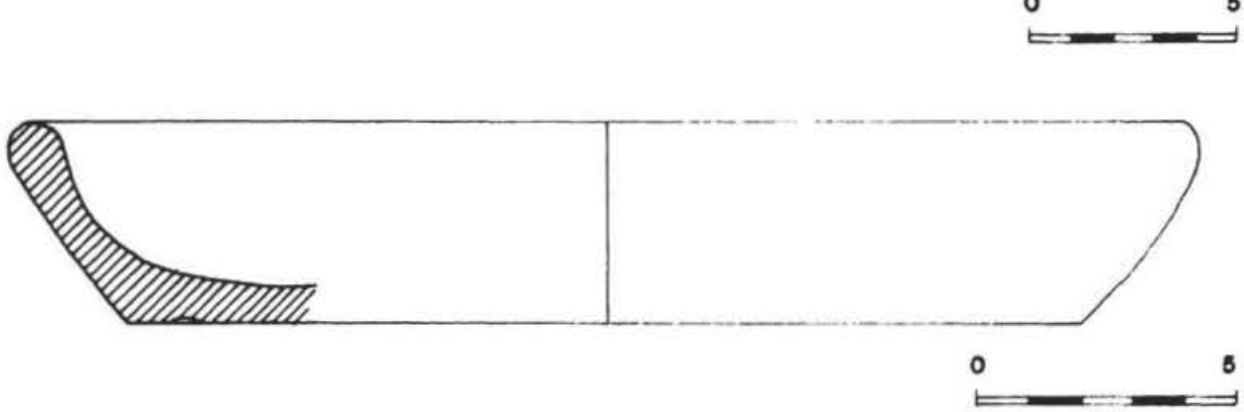

Figura 12.-Ánfora Tardorromana Tipo I de Cartago (12, asa). Terra Sigillata gris gálica tardía (13-14, forma 1 Rigoir y 15 forma, 4 Rigoir). 
can del labio y llegan hasta los hombros. En los hombros suelen llevar tituli picti con anotaciones sobre la capacidad del ánfora (Riley, 1982, 116) o con el nombre del propietario (Barnea, Iliescu y Nicolescu, 1971, 152-153).

\section{d) Cronología y dispersión}

Estas ánforas abarcan un amplio período de tiempo, ya que en general y en su zona de origen se fechan desde finales del siglo IV al siglo VII d.C. Para explicar su presencia en Gijón nos interesa sobre todo las fechas de aparición de estas ánforas en la pars occidentalis, ya que en Oriente aparecen sin ningún tipo de problemas desde el 400 d.C. por lo menos, como en Kellia (Riley, 1982, 116).

En Cartago estas ánforas se encuentran documentadas en el período vándalo, es decir, en el siglo $\mathrm{V}$ y principios del VI d.C. En este yacimiento las primeras ánforas aparecen en conjuntos pre-Teodosianos del 425 d.C., aunque su presencia aumenta en contextos del siglo VI d.C. (Riley, 1982, 116-118). De forma general podemos fechar su aparición en el norte de África en la primera mitad del siglo $\vee$ d.C., no sólo en Cártago, sino también en Uthica (Keay, 1984, 272). En el Baptisterio de Albenga se documentaron en el primer cuarto del siglo V d.C. (Keay, 1984, 272), así como en la Magna Mater donde también se fechan en el siglo $\vee$ d.C. En Nápoles aparecen desde mediados del siglo $\mathrm{V}$ a finales del VI d.C. o incluso inicios del VII d.C. (Panella, 1986, 270). Las ánforas sardas son algo más modernas de mediados del siglo VI d.C., con los ejemplares de Porto Torres (Panella, 1986, 270). En Malta también son del siglo VI d.C. como las de Tas Silq en contextos fechados por formas tardías de t.s.a. (Keay, 1984, 272). En la costa francesa están los ejemplares de La Bourse (Marsella), con dos versiones de este mismo ánfora, una temprana (Bonifay, 1986, 270) y otra más tardía. De esta última se conocen otros ejemplares franceses de Saint-Blaise, Toulón y Saint-Raphaël (Bonifay, 1986, 290).

Según Keay $(1984,271)$ la primera aparición de este tipo de ánforas en las costas peninsulares sería a finales del siglo $\vee$ d.C. en el claustro de la catedral de Tarragona, ya que este tipo de cerámica estaba ausente del cementerio paleocristiano de Tarragona fechado entre finales del IV y mediados del $\vee$ d.C. El hallazgo del vertedero de la calle Vila-Romá de Tarragona corrige esta afirmación, y estas ánforas se pueden fechar sin problemas desde la primera mitad del siglo V d.C. en Tarragona (VV.AA., 1989, 280). En la villa de Can Bosc de Basea (Tarragona) se hallaron en contextos de finales del IV y mediados del V d.C. En Ampurias son del siglo VI d.C. en general. En Rosas se atestiguan en niveles fechados antes de mediados del VI d.C., al igual que en la villa de Vilauba (Camós) (Keay, 1984, 271). En otros yacimientos donde existen estas ánforas se fechan de forma general en el siglo VI d.C. o inicios del vil d.C. como las del fondeadero de cabo Higuer (Hondarribia, San Sebastián) clasificadas como tipo Beltrán 82 (Benito, 1988, 132), o en Cartagena (Roldán, López y Vidal, 1991, 314, fig. 5, 1) datada como en Cataluña desde finales del siglo $\mathrm{V}$ hasta finales del VI d.C. La más antigua peninsular es la del vertedero de la $\mathrm{c} /$ Duque de Cartagena, fechada en la segunda mitad del siglo VI d.C. e inicios del VII d.C. (Laiz y Berrocal, 1991, 336-337, Lám. 6, 3) y las menorquinas de Cales Coves (Alayor) (Fernández Miranda y Belén, 1979, 116, fig. 53, 7), Favaritx y puerto de Mahón.

Los hallazgos más modernos de estas ánforas se encuentran en Tocra (Cirenaica) con ejemplares de mediados del siglo VII d.C. (Boardman y Hayes, 1973, 116-117). Al parecer este án- 
fora perdura en un tipo tardío, bastante semejante al de los siglos $\vee$ y VI d.C. y que se fecha, por su aparición en el depósito XXIII de las excavaciones de la Universidad de Michigan, en el siglo VII d.C. (Hayes, 1978b, 50, fig. 11, 2). En Saraçhane (Estambul) se datan a en mediados del siglo vil d.C. entre el 650 y 670 d.C. (Hayes, 1968, 203 y 215 ). A pesar de estas pruebas arqueológicas Fulford y Peacock piensan que estas ánforas en contextos del siglo VII d.C. deberían considerarse como piezas residuales (Fulford y Peacock, 1984, 200).
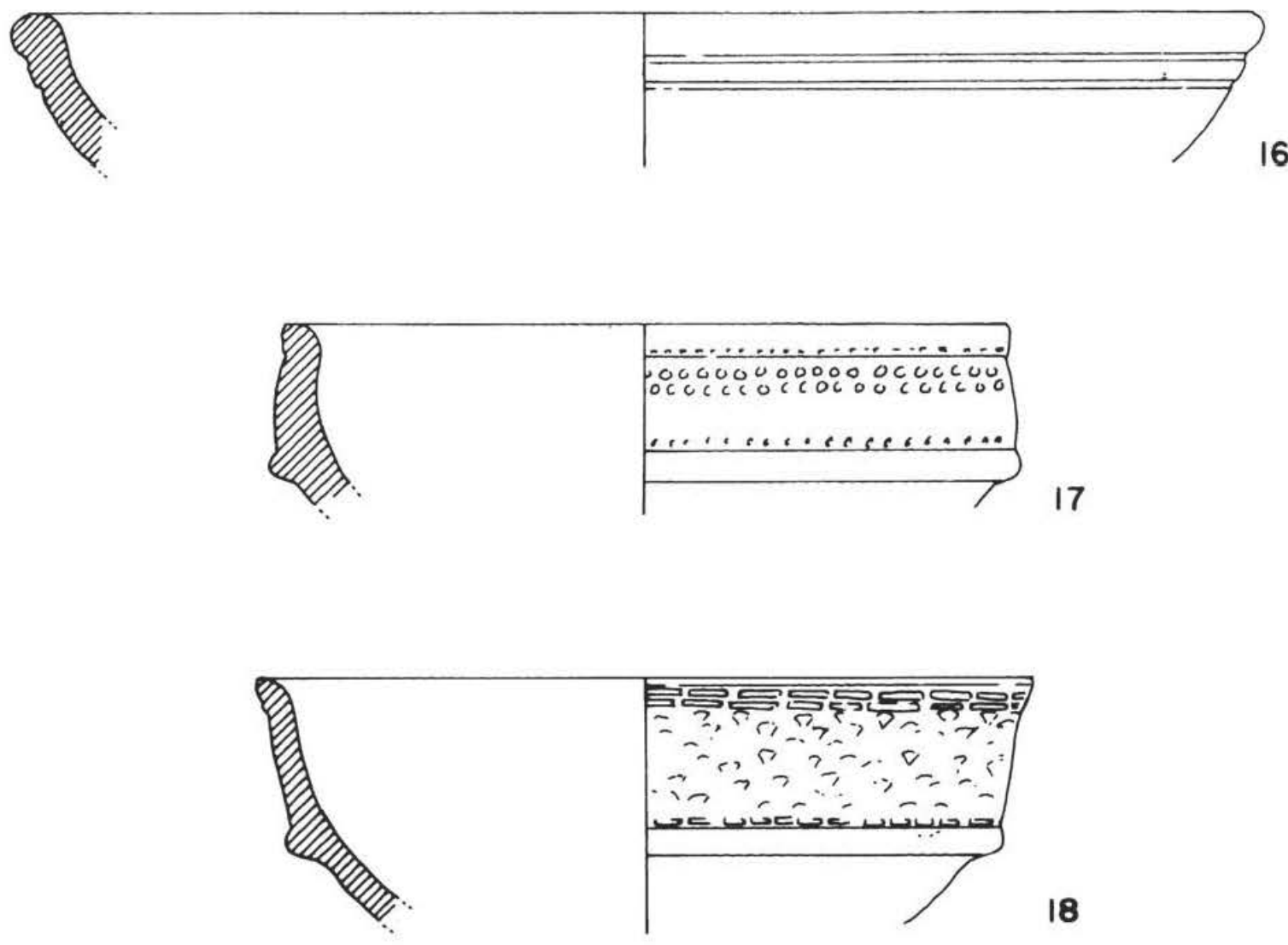

18
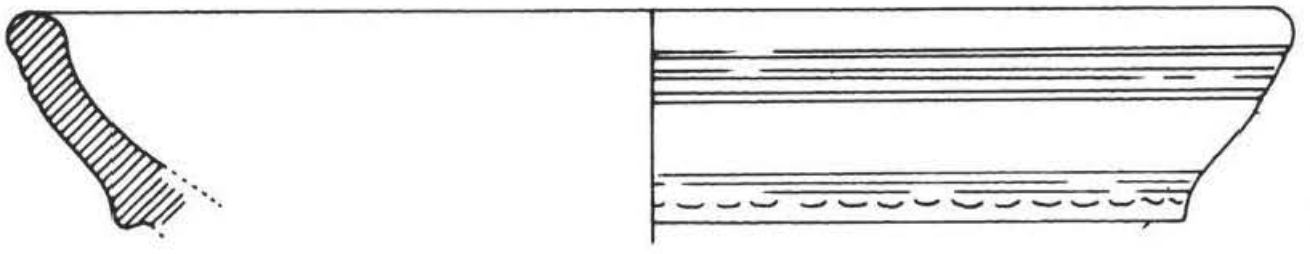

19

0

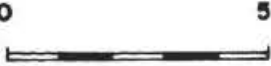

Figura 13.-Terra Sigillata gris gálica tardía (16, forma 4 Rigoir, 17-19, forma 16 Rigoir). 
Por último, y en general podemos decir, tras el hallazgo de Gijón ${ }^{26}$ y la identificación de las ánforas del fondeadero de cabo Higuer (San Sebastián) como ánforas importadas de la región de Antioquía, que el mapa de dispersión enunciado por distintos autores debe ampliarse (fig. 6), puesto que además tenemos noticia del hallazgo en las costas gallegas de otras ánforas orientales ${ }^{27}$.

\section{CONCLUSIONES}

La presencia de este tipo de importaciones en Gijón puede justificarse a través de dos tipos de vías de penetración: una claramente terrestre a partir de las costas tarraconenses, el valle del Ebro y la ruta transversal de la meseta hasta Asturica Augusta (Alonso y Fernández Ochoa, 1988, 368). Y otra netamente marítima fruto del mantenimiento de un tráfico regular a lo largo de las costas atlánticas y cantábricas peninsulares.

Existen una serie de pruebas arqueológicas que nos inclinan a aceptar esta última hipótesis de penetración marítima en detrimento de la vía terrestre desde el Mediterráneo. Estos indicios se concretan en tres yacimientos modélicos, como son el de Gijón (Asturias), Burdeos (Litoral atlántico francés) y Tintagel (Sur Islas Británicas). En todos ellos convergen una serie de características: en primer lugar, su ubicación costera atlántica, en segundo lugar se comprueba cómo en estos yacimientos existen importaciones de idéntica procedencia (t.s.a., t.s.f.t., t.s.g.g.t. y ánforas orientales), que cronológicamente responde al mismo momento histórico, y por último que probablemente fueron puntos (puertos de escala) de una misma red comercial atlántica. Además de los yacimientos-modelo citados no se pueden olvidar los hallazgos de distintas importaciones mediterráneas que jalonan la costa atlántica galaico-lusitana (Naveiro, 1991), y que reforzarían esta hipótesis.

A medida que avanzan las investigaciones sobre los hallazgos romanos en la costa cantábrica se afianza la idea de la estrecha relación entre los materiales arqueológicos de la costa Aquitana, las costas inglesas y galesas (Redde, 1979,481 ) y la costa septentrional española. Tal sería el caso de la zona de Oiasso (cabo Higuer) (Benito, 1988, 159) al que hemos de sumar el de Gijón tras los hallazgos de las producciones cerámicas aquitanas en este yacimiento. En este senti-

26 Dentro del lote gijonés, además de los fragmentos de ánforas tipo Cartago 1, se halló un pequeño fragmento de pared acanalada que posiblemente pertenecería a las denominadas ánforas de Gaza ( $C$ Carthage Late Roman Amphorae 4»), pero debido a la pequeñez del fragmento que imposibilita un análisis ceramológico este extremo no se puede confirmar.

27 Sabemos de la existencia de ánforas orientales en Galicia (Naveiro, 1991, 67) pero por el momento constituyen un problema ya que aparecen definidas como «restos de ánforas palestinianas o bizantinas» en A. Lanzada (Naveiro, 1991, fig. 15, 23), Cidadela y Taboada.

El adjetivo de palestinas puede estar haciendo referencia al ánfora tardorromana tipo 566 de Cartago ("Cartaghe Late Roman Amphora 5 ó 6») o también a la denominada ánfora de Gaza ( Carthage Late Roman Amphora $4 »$ ). Su presencia en las costas gallegas, aunque no sepamos al tipo exacto al que pertenece, es significativa, ya que estas ánforas pudieron, por la zona de donde proceden, llegar dentro de los mismos cargamentos a Occidente, como lo prueban los hallazgos de ánforas tardorromanas palestinas o tipo 5 de Cartago en Cartagena (Laiz y Berrocal, 1991, 335, Lám. 6, 1) o las de Gaza o ánfora tardorromana tipo 4 de Cartago, en el vertedero de la calle Vila-Romá de Tarragona (VV.AA., 1989, 284). En ambos yacimientos estas ánforas aparecen asociadas al ánfora de la región de Antioquía. 

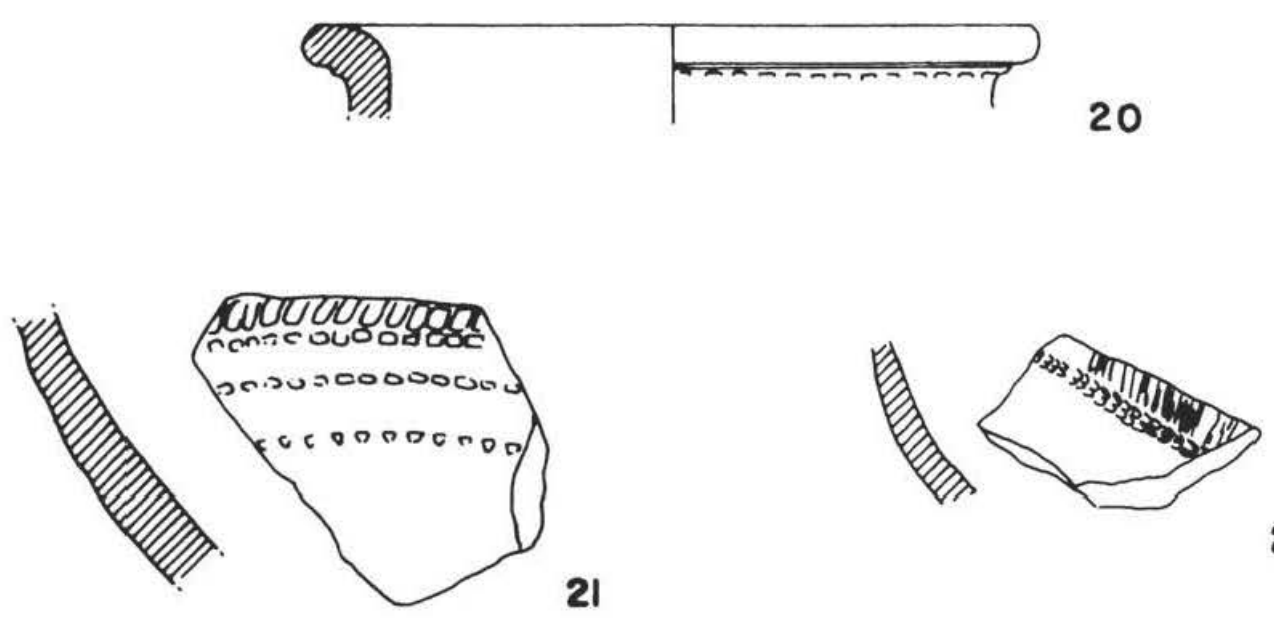

21

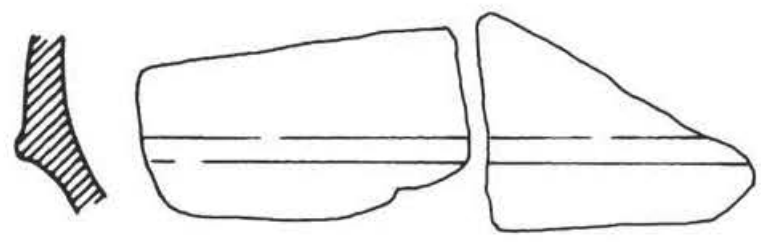

23
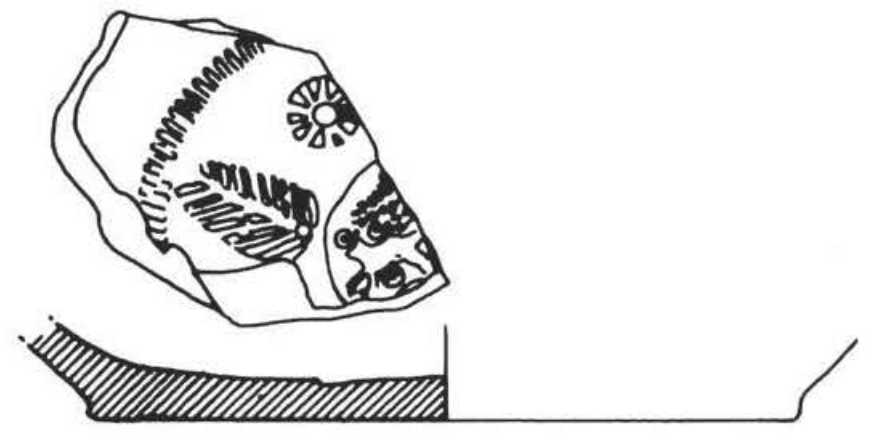

26

Figura 14.-Terra Sigillata gris gálica tardía (20, Rigoir 18, 21-22, paredes decoradas a ruedecilla, 23 , pared carenada y 26 , base con estampilla). 
do nos parece importante señalar que Gijón marca en la actualidad el punto más occidental de la presencia de la t.s.g.t., además este tipo cerámico está muy bien representado en Gijón, siendo claramente el mayoritario dentro de las importaciones, tal y como se muestra en la figura 8.

Por lo que respecta a la configuración histórica de la ciudad de Gijón, las piezas que hemos estudiado manifiestan un hecho importante: la continuidad de la ocupación de la zona desde época romana hasta los primeros años de la dominación visigoda. El hecho de que la ciudad se mantenga viva en el período tardoantiguo explica, en cierta medida, que sea Gijón la fortaleza que ocupe Munuza (durante unos pocos años) en los inicios de la Reconquista, tal y como lo refieren las crónicas altomedievales. Los musulmanes no ocuparían un universo arruinado, sino un lugar protegido y que había tenido alguna significación en época goda (Fernández Ochoa, 1992).

\section{CATÁLOGO DE PIEZAS $2 x$}

1. Plato de t.s.a. D,. Pasta granulosa. Engobe aplicado en todo el interior de la pieza y en el exterior del borde. Pasta y engobe de color N-37. Forma 104 Hayes, variante Gijón. Diám. del borde $=442 \mathrm{~mm}$. (Sector B/A(1-2)E/N-III/n." inv.: 2018). Fig. 10.

2. Fragmento de borde de t.s.a. D. Pasta granulosa. Engobe aplicado en el interior de la pieza y en el exterior del borde. Pasta y engobe color N-37. Forma 104 Hayes, variante Gijón. Diám. del borde $=444$ $\mathrm{mm}$. (Sector B/A(1-2)E/N-III/n." inv.: 2017). Fig. 10 .

3. Fragmento de borde de t.s.a. $D_{1}$. Pasta granulosa. Engobe aplicado en todo el interior de la pieza y en el exterior del borde. Pasta y engobe color N-37. Forma Hayes $91 \mathrm{C}$. Diám. del borde $=216 \mathrm{~mm}$. (Sector E/Z-4/N-V/n." inv.: 7806). Fig. 11.

4. Fragmento de borde de t.s.a. $D_{2}$. Pasta granulosa. El engobe se conserva en el interior de la pieza. Pasta color M-39 y engobe color P-39. Forma Hayes 99. Diám. del borde $=232 \mathrm{~mm}$. (Sector E/Z-7/N$1 /$ n." inv.: 6555). Fig. 11.

5. Fragmento de pared de t.s.a. $\mathrm{D}_{2}$. Pasta muy decantada de color $\mathrm{N}-39$. El engobe se conserva en el interior de la pieza y es de color P-19. (Sector E/Z-7/N-II/n." inv.: 6565). Fig. 11.

6. Fragmento de pared de t.s.a. $\mathrm{D}_{1}$. Pasta granulosa de color $\mathrm{N}-35$, con desgrasantes de pequeño tamaño de cuarzo, mica, negros y rojos. El engobe se conserva en el interior de la pieza y es de color M-39. Decoración estampillada del estilo A(ii)/(iii) de Hayes. (Sector E/Z-4/N-IV/n." inv.: 6260). Fig. 11.

7. Fragmento de pared de fuente de t.s.a. $\mathrm{D}_{2}$. Pasta muy depurada de color P-39, con desgrasantes muy finos de cuarzo. El engobe se conserva en el interior, de color P-39. (Sector E/Z-4/N-III/n." inv.: 6I64).

8. Fragmento de borde de una fuente de t.s.f.t. Pasta muy depurada de color $\mathrm{N}-39$. El engobe se conserva en el interior de la pieza y en la parte inferior del borde en su zona externa, es de color R-25. Forma Hayes 3E. Diám. del borde $=260 \mathrm{~mm}$. (Sector E/Z-3/N-III/n. ${ }^{\circ}$ inv.: 6018). Fig. 11 .

9. Fragmento de pared de una ánfora oriental tipo Cartago 1. Pasta granulosa con numerosos desgrasantes de cuarzo, calcitas e inclusiones de color negro. La pasta en el exterior es de color L-75 y en el interior M-67. (Sector E/Z-4/N-VIII/n. ${ }^{\circ}$ inv.: 7850). Fig. 11.

10. Fragmento de pared de una ánfora oriental tipo Cartago 1. Pasta granulosa con numerosos desgrasantes de cuarzo, calcitas e inclusiones de color negro. La pasta en el exterior es de color L-75 y en el interior M-69. (Sector E/Z-8/N-III/n. ${ }^{\circ}$ inv.: 6776).

11. Seis fragmentos de pared de ánfora oriental tipo Cartago 1. Pasta granulosa con numerosos desgrasantes de cuarzo, calcitas e inclusiones de color negro. La pasta en el exterior es de color L-70 y en el interior L-53. (Sector $\mathrm{E} / \mathrm{Z}-4 / \mathrm{N}-\mathrm{V} / \mathrm{n} .^{\circ}$ inv.: 7812 ).

${ }^{28}$ Para la definición de los colores de las pastas y engobes hemos empleado el código de A, Cailleux: "Code des couleurs des sols». Ed. Boubée. 

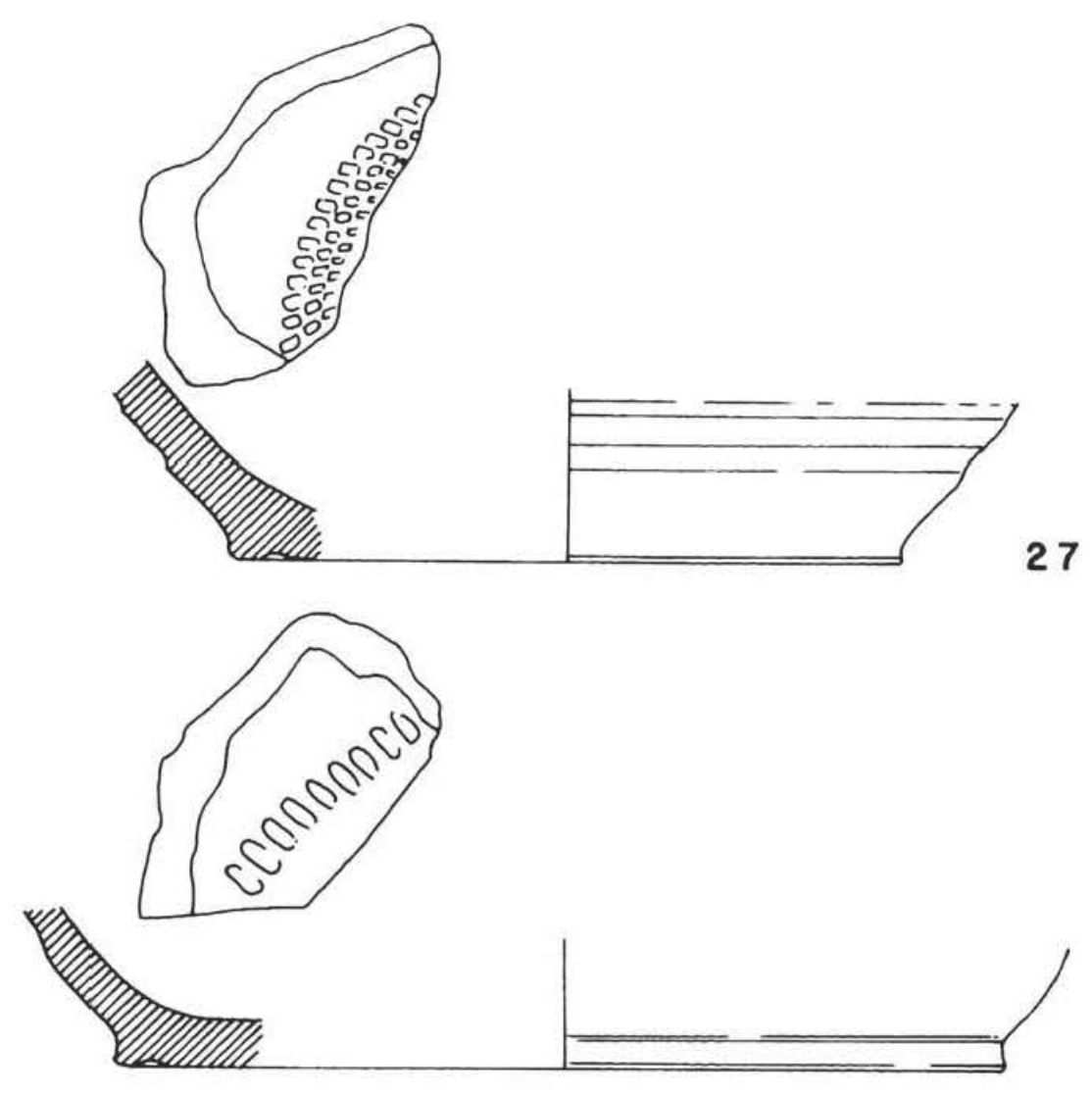

28
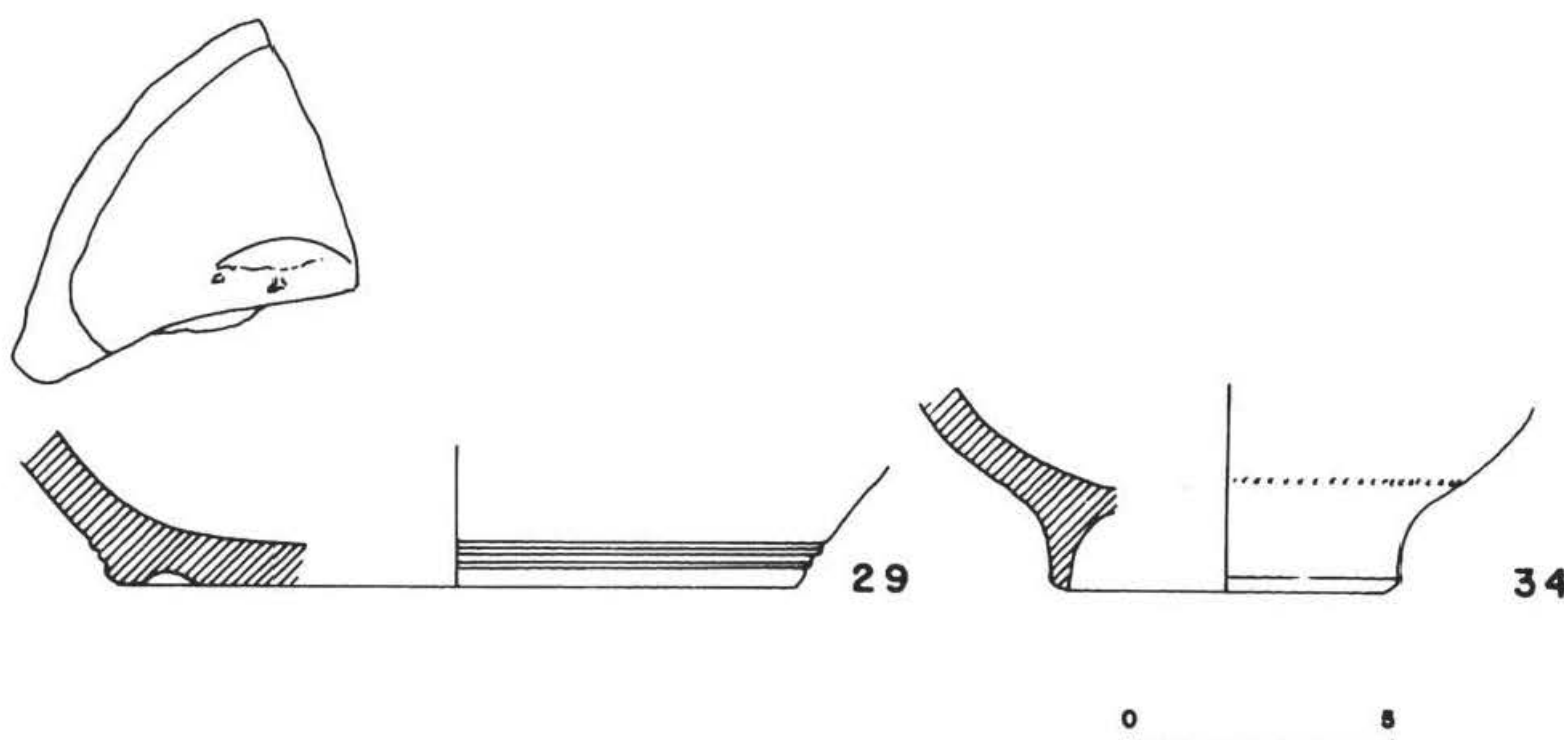

s

Figura 15.-Terra Sigillata gris gálica tardía (27-29 y 34, bases decoradas a ruedecilla). 
12. Asa de una ánfora oriental tipo Cartago 1. Pasta granulosa con numerosos desgrasantes de cuarzo, calcitas e inclusiones de color negro. La pasta es de color M-69. (Sector E/Z-4/N-V/n." inv.: 7812). Fig. 12.

13. Fragmento de borde de una fuente de t.s.g.g.t. Pasta muy depurada de color L-73, con desgrasantes muy pequeños micáceos y de cuarzo. El fragmento está muy rodado. Forma similar a una Rigoir 1. Diám. del borde $=326 \mathrm{~mm}$. (Sector E/Z-7/N-III/n. ${ }^{\circ}$ inv.: 6537). Fig. 12.

14. Fragmento de borde de una fuente de t.s.g.g.t. Pasta muy depurada de color N-31, con desgrasantes de cuarzo. El engobe está perdido. Forma similar a una Rigoir 1. Diám. del borde $=396 \mathrm{~mm}$. (Sector E/Z-4/N-IX/n.' inv.: 7880). Fig. 12.

15. Fragmento de borde de un plato de t.s.g.g.t. Pasta muy depurada de color N-73, con desgrasantes de cuarzo. El engobe de tacto jabonoso es de color T-73. Forma Rigoir 4. Diám. del borde $=220 \mathrm{~mm}$. (Sector E/Z-4/N-V/n,. ${ }^{\circ}$ inv.: 7803). Fig. 12.

16. Fragmento de borde de un plato de t.s.g.g.t. Pasta muy depurada de color M-73, con desgrasantes de cuarzo. El engobe se conserva en el interior y en la zona de las estrías externas, es de tacto jabonoso y de color T-73. Forma Rigoir 4. Diám. del borde = $272 \mathrm{~mm}$. (Sector E/Z-2/N-VIII/n. ${ }^{\circ}$ inv.: 5738). Fig. 13.

17. Fragmento de borde de un cuenco de t.s.g.g.t. Pasta muy depurada de color N-71, con desgrasantes de mica. El engobe está perdido. Forma Rigoir 16. Diám. del borde $=160 \mathrm{~mm}$. (Sector E/Z-4/NVII/n.” inv.: 7840). Fig. 13.

18. Fragmento de borde de un cuenco de t.s.g.g.t. Pasta muy depurada de color N-71, con desgrasantes finos de cuarzo. El engobe es de color T-73, está muy mal conservado; en el interior tiene tacto jabonoso y en el exterior aparece espatulado. Forma Rigoir 16. Diám. del borde $=172 \mathrm{~mm}$. (Sector E/Z$4 / \mathrm{N}-\mathrm{VI} / \mathrm{n} .^{\circ}$ inv.: 6248). Fig. 13.

19. Fragmento de borde de un cuenco de t.s.g.g.t. Pasta muy depurada, de color M-73, con desgrasantes finos de cuarzo. El engobe de tacto jabonoso es de color T-73, conservado en el interior y en las estrías de la cara externa. Forma Rigoir 16. Diám. del borde $=237 \mathrm{~mm}$. (Sector E/Z-4/N-II/n.` inv.: 6322). Fig. 13.

20. Fragmento de borde de un cuenco de t.s.g.g.t. Pasta muy depurada, de color M-73, con desgrasantes finos de cuarzo. El engobe es de color T-73, está muy mal conservado. Forma Rigoir 18. Diám. del borde $=136 \mathrm{~mm}$. (Sector E/Z-4/N-VIII/n. ${ }^{\circ}$ inv.: 7850). Fig. 14.

21. Fragmento de pared decorada de t.s.g.g.t. Pasta depurada, de color N-71, con desgrasantes finos de cuarzo. Conserva el engobe en la parte externa de la pieza, de color T-73. (Sector E/Z-4/N-VIII/n. ${ }^{\circ}$ inv.: 7860). Fig. 14.

22. Fragmento de pared decorada de t.s.g.g.t. Pasta muy depurada, de color M-73, con desgrasantes finos de cuarzo. No conserva el engobe. (Sector E/Z-4/N-VIII/n. ${ }^{\circ}$ inv.: 7849). Fig. 14.

23. Fragmento de pared de t.s.g.g.t. Pasta muy depurada, de color M-31, con pequeños desgrasantes de cal y mica. En la carena conserva insignificantes restos del engobe. (Sector $\mathrm{E} / \mathrm{Z}-7 / \mathrm{N}-\mathrm{III} / \mathrm{n}^{\circ}{ }^{\circ}$ inv.: 6537). Fig. 14.

24. Fragmento de pared de t.s.g.g.t. Pasta muy depurada, de color M-73, con desgrasantes finos de cuarzo. El engobe de tacto jabonoso es de color T-73. (Sector E/Z-7/N-III/n. ${ }^{\circ}$ inv.: 6515).

25. Fragmento de pared de t.s.g.g.t. Pasta muy depurada, de color M-73, con desgrasantes de cuarzo. El engobe es de tacto jabonoso y de color T-73. (Sector C/C-2/N-IV/n. ${ }^{\circ}$ inv.: 614).

26. Fragmento de base de un plato decorado de t.s.g.g.t. Pasta muy depurada, de color M-73, con desgrasantes finos de cuarzo. El engobe es de tacto jabonoso y de color T-73. Diám. de la base $=135 \mathrm{~mm}$. (Sector E/Z-4/N-III/n. ${ }^{\circ}$ inv.: 6574). Fig. 14.

27. Fragmento de base de un plato decorado de t.s.g.g.t. Pasta muy depurada, de color L-73. El engobe es de tacto jabonoso y de color T-71. Diám. de la base $=130 \mathrm{~mm}$. (Sector E/Z-7/N-III/n. ${ }^{\circ}$ inv.: 6537). Fig. 15.

28. Fragmento de base de un plato decorado de t.s.g.g.t. Pasta muy depurada, de color L-73. Conserva restos de engobe en ambas superficies, de color T-73. Diám. de la base $=170 \mathrm{~mm}$. (Sector E/Z-4/N$\mathrm{VIII} / \mathrm{n} .^{\circ}$ inv.: 7860). Fig. 15.

29. Fragmento de base de un plato decorado de t.s.g.g.t. Pasta muy depurada, de color M-73. El engobe es de tacto jabonoso y de color T-73. Diám. de la base $=130 \mathrm{~mm}$. (Sector $\mathrm{E} / \mathrm{Z}-4 / \mathrm{N}-\mathrm{VII} / \mathrm{n}$. $^{\circ}$ inv.: 7840). Fig. 15. 


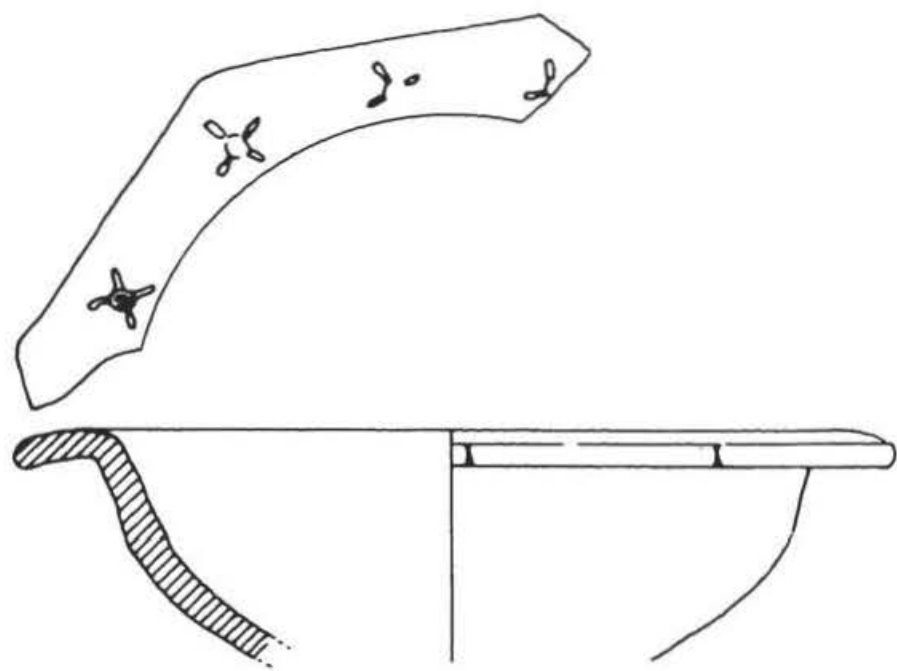

38

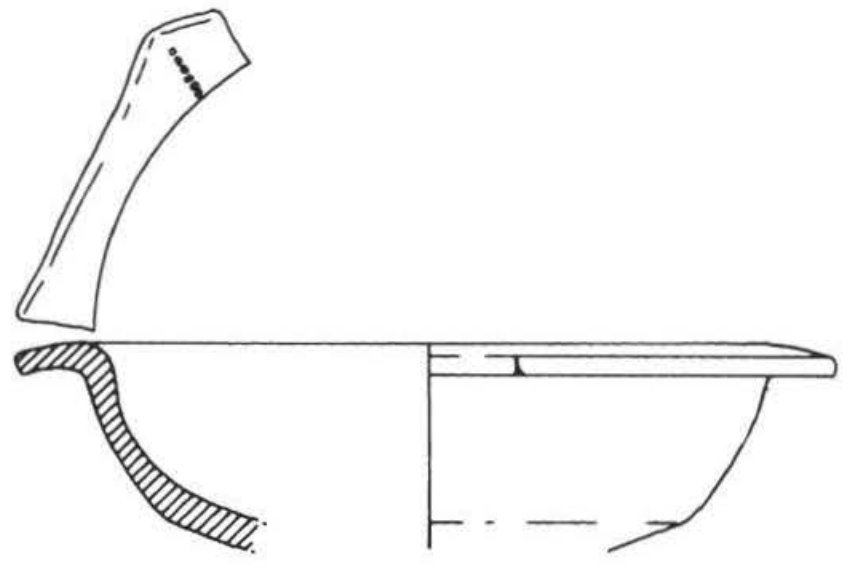

39

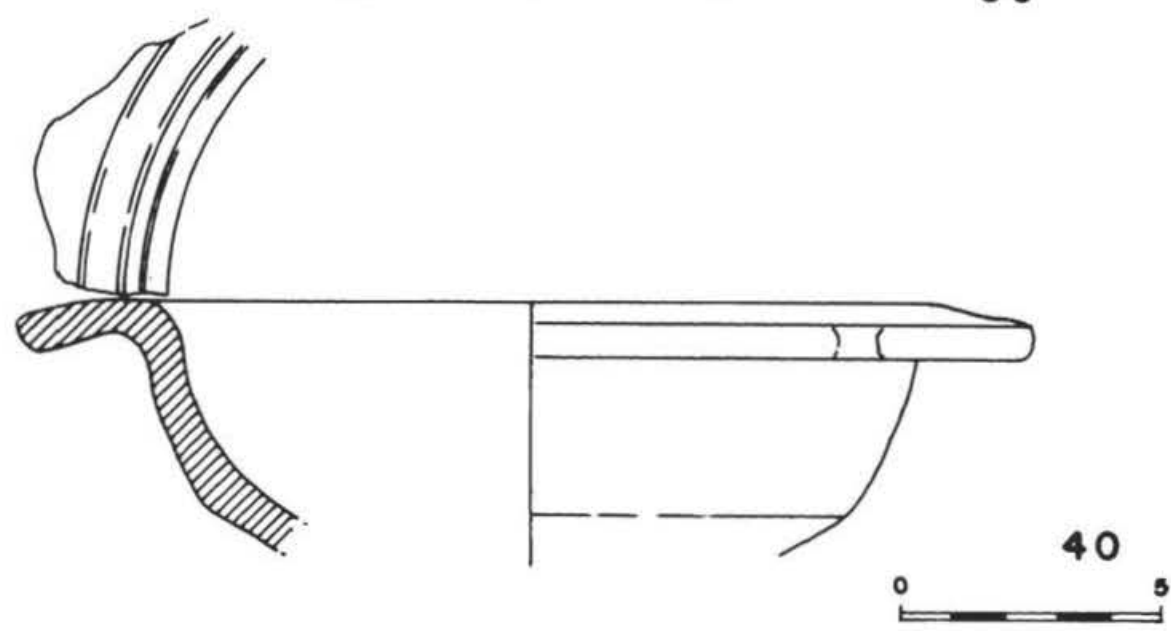

Figura 16.-Imitaciones regionales de Terra Sigillata gris gálica tardía (38-40). 
30. Fragmento de base de un plato de t.s.g.g.t. Pasta muy depurada, de color L-73, con desgrasantes finos de cuarzo. El engobe es de tacto jabonoso y de color T-73. Diám. de la base $=112 \mathrm{~mm}$. (Sector E/Z$4 / \mathrm{N}-\mathrm{V} / \mathrm{n}$." inv.: 7802 ).

31. Fragmento de base de un plato de t.s.g.g.t. Pasta muy depurada, de color N-31, con desgrasantes finos de cuarzo. No conserva el engobe. Diám. de la base $=170 \mathrm{~mm}$. (Sector $\mathrm{E} / \mathrm{Z}-4 / \mathrm{N}-\mathrm{VIII} / \mathrm{n}$." inv.: $7860)$.

32. Fragmento de base de t.s.g.g.t. Pasta muy depurada, de color M-73, con desgrasantes finos de cuarz.o. No conserva el engobe. Diám. de la base $=35 \mathrm{~mm}$. (Sector E/Z-4/N-II/n. inv.: 6117),

33. Fragmento de base de t.s.g.g.t. Pasta muy depurada, de color M-73, con desgrasantes muy finos. No conserva el engobe. Diám. de la base $=65 \mathrm{~mm}$. (Sector E/Z-4/N-IX/n." inv.: 7894).

34. Fragmento de base de cuenco de t.s.g.g.t. Pasta muy depurada, de color N-31, con desgrasantes medios de cal. El engobe está bruñido, tiene tacto jabonoso y es de color T-73. Diám. de la base $=60 \mathrm{~mm}$. (Sector E/Z-6/N-II/n. ${ }^{\circ}$ inv.: 6415a). Fig. 15.

35. Fragmento de base de cuenco de t.s.g.g.t. Pasta muy depurada, de color M-73, con desgrasantes finos de cuarzo. Engobe de tacto jabonoso y de color T-73. Diám. de la base $=56 \mathrm{~mm}$. (Sector $\mathrm{E} / \mathrm{Z}-4 / \mathrm{N}$ V/n." inv.: 7821).

36. Fragmento de base de cuenco de t.s.g.g.t. Pasta muy depurada, de color M-73, con desgrasantes finos de cuarzo. Engobe de tacto jabonoso y de color T-73. Diám. de la base $=56 \mathrm{~mm}$. (Sector E/Z-4/N V/n." inv.: 7803).

37. Fragmento de base de cuenco de t.s.g.g.t. Pasta muy depurada, de color M-73. no conserva el engobe. Diám. de la base $=90 \mathrm{~mm}$. (Sector E/Z-7/N-III/n." inv.: 6537).

38. Fragmento de borde y pared de un cuenco de imitación de t.s.g.g.t. Cocción reductora irregular. Pasta depurada, de color gris pardusco, con desgrasantes medios de cuarzo. Las superficies son rugosas. Decoración estampillada en la parte superior del borde: aspas cruzadas con círculo central. Forma prototipo Hayes 97. Diám. del borde = 144 mm. (Sector E/Z-4/N-IX/n. ${ }^{\circ}$ inv.: 7894). Fig. 16.

39. Fragmento de borde y pared de un cuenco de imitación de t.s.g.g.t. Cocción reductora. Pasta depurada, de color grisáceo, con desgrasantes micáceos. Restos de decoración impresa en el borde. Forma prototipo Hayes 97. Diám. del borde $=128 \mathrm{~mm}$. (Sector E/Z-4/N-IX/n. ${ }^{\circ}$ inv.: 7880). Fig. 16.

40. Fragmento de borde y pared de un cuenco de imitación de t.s.g.g.t. Cocción reductora irregular. Pasta depurada, de color gris pardusco y ocre, con desgrasantes medios de cuarzo. Las superficies son rugosas. Forma prototipo Hayes 97 . Diám. del borde $=140 \mathrm{~mm}$. (Sector E/Z-4/N-IX/n. ${ }^{\circ}$ inv.: 7894). Fig. 16.

\section{ANEXO: ANÁLISIS DE DOS ÁNFORAS TARDORROMANAS DE GIJÓN}

Las muestras presentadas a examen se han sometido, una vez molidas en mortero de ágata y tamizadas, recogiendo la fracción próxima a $20 \mu$, a dos técnicas analíticas:

1. Difracción de Rayos X, en equipo Philips PW 1035 con anticátodo de cobre y registro gráfico, sobre muestra pulverizada, realizando el diafractograma a $40 \mathrm{KV}$ y $20 \mathrm{MA}$.

2. Separación de minerales mediante líquidos densos, siendo el líquido empleado bromoformo con densidad $2.89 \mathrm{~g} / \mathrm{cc}$. Se estudian las dos fracciones, ligera (densidad inferior a $2.89 \mathrm{~g} / \mathrm{cc}$ ) y pesada (minerales con densidad superior a $2.89 \mathrm{~g} / \mathrm{cc}$ ).

\section{Difracción de Rayos $X$}

La aplicación de esta técnica a las dos muestras 1 (n. ${ }^{\circ}$ cat. 10) y 2 (n. ${ }^{\circ}$ cat. 9), proporciona el mismo resultado cualitativo, que se representa en el gráfico 2 . En ella se identifican las líneas de los componentes minerales, según G. W. Brindley y G. Brown (1980, 317). El análisis semicuantitativo es: 

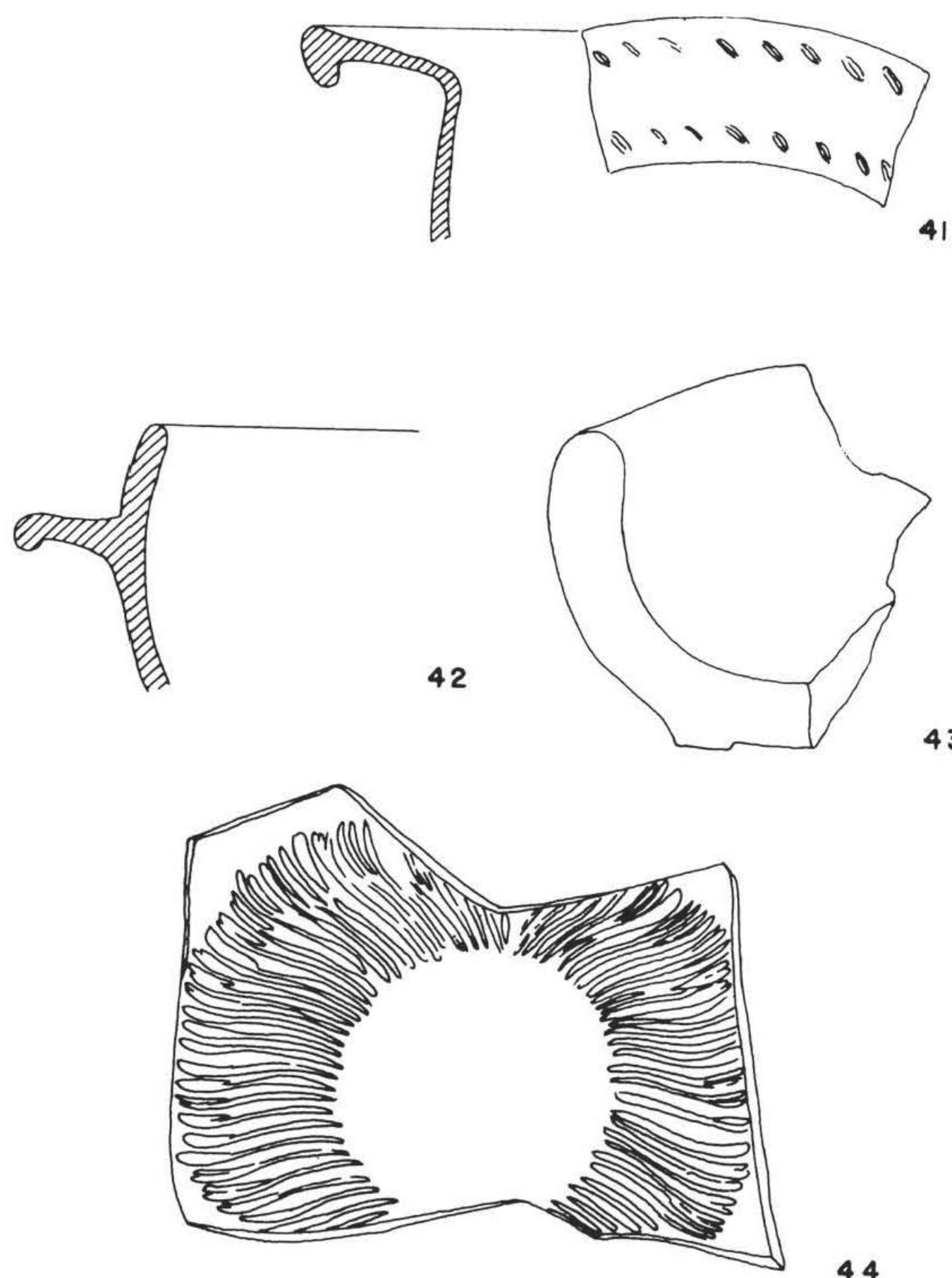

Figura 17.-Terra Sigillata Africana D y Terra Sigillata gris gálica tardía. 41, Forma 73A Hayes, 42 forma $91 \mathrm{C}$ Hayes y 44 , base forma 91 Hayes. 43 , Terra Sigillata gris gálica tardía, forma 4 Rigoir. 


\begin{tabular}{lcc} 
& MUESTRA 1 $(\%)$ & MUESTRA 2 $(\%)$ \\
\hline Cuarzo & 49 & 53 \\
Calcita & 18 & 15 \\
Dolomita & 20 & 15 \\
Feldespato potásico & 8 & 12 \\
Piroxenos & 5 & 5 \\
\hline
\end{tabular}
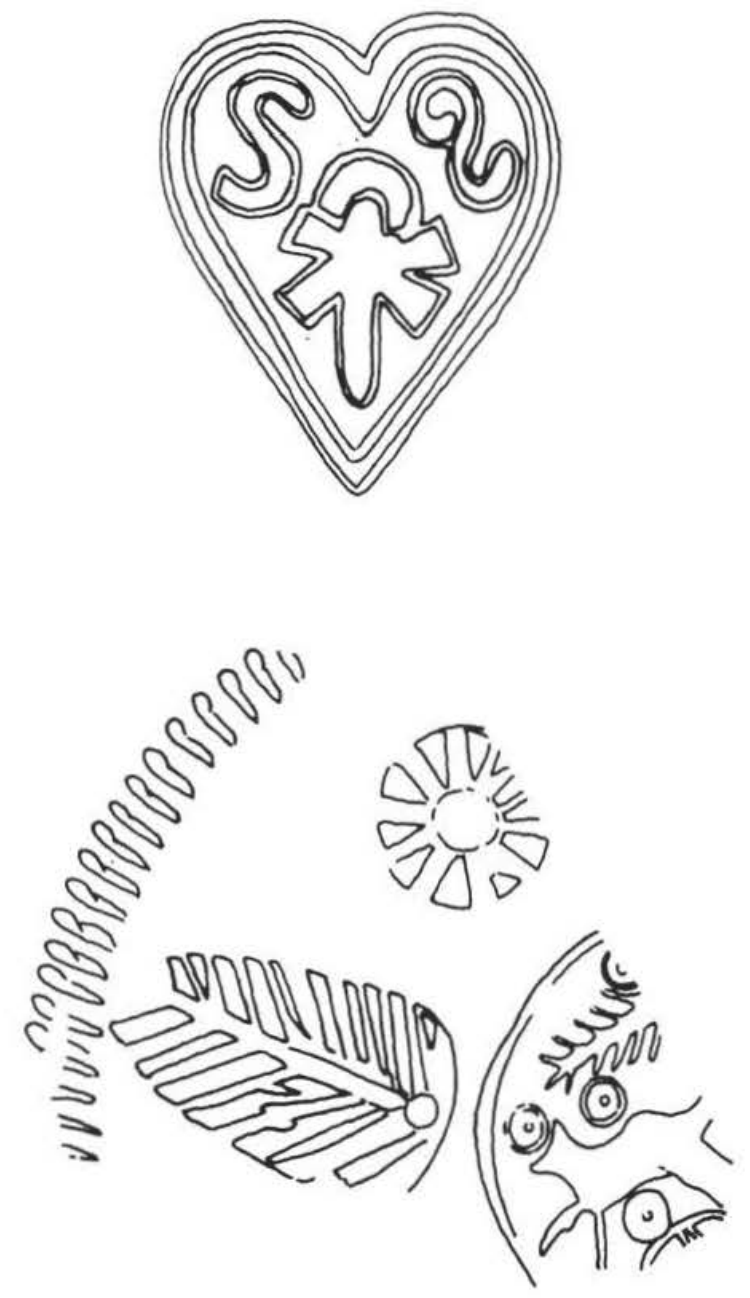

26

Figura 18.-Punzones de la Terra Sigillata Africana D (1) y de Terra Sigillata gálica tardía (26). 


\section{Separación mediante bromoformo}

El método empleado es el seguido por M. P. Jones y M. G. Fleming (1965, 102). Consiste en dispersar la muestra molida en bromoformo y separar la fracción que sobrenada, ligera y la que precipita, pesada, para luego una vez secadas, colocarlas en porta-objetos homogeneizadas con bálsamo de Canadá, proceder a la observación microscópica y a su reconocimiento.

FRACCIÓN LIGERA (DENSIDAD $<2.89 \mathrm{~g} / \mathrm{cc}$ )

\begin{tabular}{lcc}
\hline & MUESTRA 1 & MUESTRA 2 \\
\hline Calcita & $23 / 50$ & $11 / 50$ \\
Biotita & $3 / 50$ & $6 / 50$ \\
Feldespato potásico & $3 / 50$ & $5 / 50$ \\
Cuarzo & $21 / 50$ & $28 / 50$ \\
\hline
\end{tabular}

FRACCIÓN PESADA (DENSIDAD > 2,89 g/cc)

\begin{tabular}{lcc}
\hline & MUESTRA 1 & MUESTRA 2 \\
\hline Turmalina & $26 / 50$ & $8 / 50$ \\
Rutilo & $10 / 50$ & $18 / 50$ \\
Hiperstena & $3 / 50$ & - \\
Augita & $10 / 50$ & $22 / 50$ \\
Opacos & $1 / 50$ & $2 / 50$ \\
\hline
\end{tabular}

La presencia de los piroxenos hiperstena $(\mathrm{Mg}, \mathrm{Fe})_{2}\left[\mathrm{Si}_{2} \mathrm{O}_{6}\right]$ y augita $\mathrm{Ca}(\mathrm{Mg}, \mathrm{Fe})(\mathrm{SiO})_{2} I(\mathrm{Al}$, $\mathrm{Fe})_{2} \mathrm{O}_{3} \mid \mathrm{x}$, confïrma la posible ocurrencia de ellos en contacto con calizas de origen básico. Además en las biotitas, que se encuentran muy alteradas, son numerosas las inclusiones de circón.

Al comparar los resultados obtenidos con los propuestos por D. F. Williams $(1982,99-110)$ los fragmentos de cerámica aquí estudiados están próximos al ánfora II de la serie británica (Bii) que corresponde al ánfora tardorromana tipo 1 de Cartago, donde la característica primordial es la presencia de piroxenos y caliza, pudiendo tener como área fuente el Mediterráneo Oriental y el entorno del mar Negro.

Hay que destacar que los dos fragmentos estudiados no pertenecen a la misma pieza al tener una diferente composición cuantitativa. No obstante, ambas muestras se puede decir que no han superado en su cocción una temperatura superior a $850^{\circ} \mathrm{C}$, al existir en su estructura calcita, mineral que se destruye próximo a la mencionada temperatura.

\section{BIBLIOGRAFÍA}

AlARÇAO, A., y J. (1963-64): «Cerâmica estampada vermelha de Conimbriga». Arquivo de Beja, XXXXI. Beja, 81-100.

Alcock, L. (1964): «Dinas Powys». Archaeology, 17 (2). Nueva York, 104-111.

AlONSO, M. A., y FERNÁNDEZ OCHOA, C. (1988): «Cerámica africana D con decoración paleocristiana en la muralla de Gijón». Cuad. Preh. y Arq. de la U.A.M. Madrid, 339-377.

ALVARGONZÁleZ, C. (1965): Las termas romanas de Gijón.

BARNEA, I.; IliesCU, D., y NiCOlescu, C. (1971): Cultura bizantina in Rômania. Bucarest.

Bendala, M., y NeGUeruela, I. (1980): «Baptisterio paleocristiano y visigodo en los Reales Alcázares de Sevilla». N.A.H., 10. Madrid, 335-379. 
Benito, A. M. (1988): “Cerámicas del yacimiento submarino de cabo de Higuer (Hondarribia)», Munibe, 40. San Sebastián, 123-163.

BOARDMAN, J., y HAYES, J. W. (1973): «Excavations at Tocra 1963-1965. The Arcaic Deposits II and Later Deposits". Vol. II. B.B.S.A.A. Atenas.

Bohigas, R., y Ruiz GUTIÉRREZ, A. (1989): «Las cerámicas visigodas de poblado en Cantabria y Palencian. Bol. Arqueol. Medieval, 3, 31-51.

Bolufer, J. (1988): «Cerámiques fines tardanes de la Punta de l'Arenal». Xábiga, 4. Jávea, 40-53.

BONIFAY, M. (1986): «Observations sur les amphores à Marseille d'après les fouilles de La Bourse (19801984)". Revue Archéologique de Narbonnaise, 19. Montpellier, 269-305.

Bourgeois, A., y MAYET, F. (1991): «Fouilles de Belo. Belo VI. Les sigillées». Collection de la Casa Velázquez. Archéologie, XIV. Madrid.

BRINDLEY, G. W., y BROWN, G. (eds.) (1980): «Crystal structures of clay minerals and their X-Ray identification». Min. Soc. John Wiley. Londres.

CABALlero ZoredA, L. (1966): Estado actual del estudio de la cerámica sigillata clara en el Mediterráneo occidental. Ampurias, XXVIII. Barcelona, 139-156.

CABALLERO ZOREDA, L. (1972): «Cerámica sigillata gris y anaranjada paleocristiana en España». Separata de Trabajos de Prehistoria, 29. Madrid.

CABALLERO ZOREDA, L. (1974): «Cerámica sigillata clara de tipo D estampada de las provincias de Murcia y Almería». Miscelánea arqueológica, 193-222.

CABAllero ZoredA, L. y ARgente Oliver, J. L. (1975): «Cerámica paleocristiana, gris y anaranjada, producida en España». T. P., 32, 113-150.

CARROCERA, E., y REQUEJO, O. (1989): «Producciones cerámicas tardías en castros y villas asturianas». Bol. Arqueol. Medieval, 3, 21-30.

CAZURro, M. (1909-1910): «Terra sigillata. Los vasos aretinos y sus imitaciones galo-romanas en Ampurias». Anuari del Institut d'Estudis Catalans, III, 296-360.

DAURA, A., y PARDO, D. (1991): «Restes romanes Baix Imperials a la conca mitjana-alta del riu Llobregat (Novesdades per a un panorama poc conegut)». Estrat, 4. Igualada, 37-60.

DECHELETTE, J. (1904): Les vases céramiques ornées de la Gaule romaine. París.

Delgado, M. (1967): Terra sigillata clara de Conímbriga. Conímbriga, VI, 47-128.

Delgado, M.; MAyet, F., y MouTinho, A. (1975): «Les Sigillées claires». En: Fouilles de Conimbriga IV. Les Sigillées. París, 249-316.

EMPEREUR, J.-Y., y PiCón, M. (1986): «A propos d'un nouvel atelier de "Late Roman C"». Figlina, 7. Lyón, 143-146.

Fernández Miranda, M., y Belén, M. (1979): «El fondeadero de Cales Coves (Menorca, Islas Baleares)», E.A.E., 101. Madrid.

FERNÁNDEZ OCHOA, C. (1992): «La muralla romana de Cimadevilla». En Los orígenes de Gijón. Gijón, 53-71.

Fulford, M. C., y PEACOCK, D. P. S. (1984): Excavations at Carthage. The British Mission, 1, 2. The Avenue of President Habib Bourguiba, Salammbo. The pottery and others ceramic object from the site. Sheffield.

GARABITO, T. (1983): «El centro de producción de sigillata hispánica tardía en Nájera». Cuadernos de Investigación. I Coloquio sobre Historia de La Rioja (1982). Tomo IX, fasc. 1. Logroño, 187-197.

HAYES, J. W. (1968): «A seventh Century Pottery group». Dumbarton Oaks Papers, 12. Washington, 203-216.

HAYES, J. W. (1972): Late Roman Pottery. A catalogue of roman fine wares. The British School at Rome. Londres.

HAYES, J. W. (1976): «Pottery: stratified groups and typology». En HuMPHREY, J. H. (ed.): Excavations at Carthage conducted by the University of Michigan, 1975. Vol. I. Ann Harbour, 47-123.

HAYES, J. W. (1977): «North African flanged bowls: a problem in the fifth-century chronology». En DORE, J., y GREENE, K. (eds.): Roman pottery studies and beyond. Papers presented to J. Gilman, July 1977. B.A.R. Suppl. series, 30. Oxford, 279-287. 
HAYES, J. W. (1978a): "Selected deposits (continued)». En HuMPHREY, J. H. (ed.): Excavations at Carthage conducted by the University of Michigan, 1975. Vol. II. Ann Harbour, 113-118.

HAYES, J. W. (1978b): «Pottery report-1976». En HumphrEY. J. H. (ed.): Excarations at Carthage conducted by the University of Michigan. 1976. Vol. IV. Ann Harbour, 23-98.

HAYES, J. W. (1980): Supplement to Late Roman Pottery. The British School at Rome. Londres.

HAYES, J. W. (1985): «New finds of late roman from the two harbours of Carthage». C.E.D.A.C. Carthage, 6. Institut National d'Archéologie et d'Art de Tunise. Cartago, 40.

JÁRREGA, R. (1987): «Notas sobre la importación (sigillata clara D) en la costa oriental de Hispania durante el siglo vi e inicios del vil d.C.». C.A.M.E.. II. Madrid, 337-344.

JÁRREGA, R. (1991 a): «Cerámicas finas tardorromanas y del Mediterráneo oriental en España. Estado de la cuestión». Anejos de Archivo Español de Arqueologia. IX. C.S.I.C. Madrid.

JÁRREGA, R. (1991b): «La comarca de L'Anoia a l'época tardo-romana. Un estat de la qüestió». Estrat, 4. Igualada, 61-82.

JONES, M. P., y FLEMING, M. G. (1965): Identification of minerals grains. Ed. Elsevier. Londres.

KEAY, S. J. (1984): «Late Roman Amphorae in the western Mediterranean. A typology and economic study: the catalan evidence». B.A.R. International series, 196. Oxford.

LAmboglia, N. (1941): «Terra Sigillata Chiara». Rivista Ingauna e Intemelia, VII. Bordighera, 7-22.

LAmboglia, N. (1958): «Nuove osservazioni sulla Terra Sigillata chiara (tipi A e B)». Rivista di Studi Liguri, XXIV (3-4). Bordighera, 257-330.

LAmboglia, N. (1963): «Nuove osservazioni sulla Terra Sigillata chiara (tipi C, lucente e D)». Rivista di Studi Liguri, XXIX (1-4). Bordighera, 145-212.

LAIZ, M. ${ }^{a}$ D., y BERROCAL, M.a C. (1991): «Un vertedero tardío en c/ Duque, 33». Arte, sociedad, economía y religión durante el Bajo Imperio y la Antigüedad tardía. Ant. y crist., VIII. Murcia, 321-340.

López Rodríguez, J. R., y Regueras Grande, F. (1987): Cerámicas tardorromanas de Villanueva de Azoague (Zamora). B.S.A.A. de Valladolid, 53. Valladolid, 115-166.

MACKENSEN, M. (1985): «Prospektion einer spätantiken sigillatatöpferei in El Mahrine/Nordtunisien». C.E.D.A.C., Carthage Bulletin, 6. Cartago, 29-39.

MACKENSEN, M. (1991): Zur Datierung mediterraner Sigillata aus der spätantiken Befestigung latrus an der unteren Donau (Die Chronologie der Late Roman C-Formen Hayes 3 A-E). Germania, 69 (1), $79-96$.

MAÑANES, T. (1980): «La cerámica tardorromana-visigoda anaranjada y gris con decoración estampada en la España Nor-occidental». Studia Archaeologica, 65. Valladolid, 215-250.

MARTín, G. (1965): «Notas preliminares sobre la terra sigillata clara de Pollentia (Mallorca)». Rei Cretaiae Romanae Fautorum, Acta VII, 71 y ss.

MARTín, G. (1966): Terra sigillata clara estampada con ruedecilla, IX, C.N.A. Valladolid, 1965. Zaragoza, 358 y ss.

MARTín, G. (1968): Comercio y producción de cerámicas finas en época imperial. Papeles de la Universidad de Valencia, 5. Valencia, 107-137.

MARTín, G. (1969): Consideraciones sobre la terra sigillata hispánica mauritana y la sigillata clara en Marruecos. Papeles del Laboratorio de Arqueología de Valencia, 6. Valencia, 151-179.

Martínez Rodríguez, A., y Matilla, G. (1988): «Poblamiento tardío en Torralba. Lorca». Arte y poblamiento en el SE peninsular. Ant. y crist., V. Murcia, 503-541.

Matilla, G. (1988): «El castillo de los Garres: una fortaleza tardía en la vega de Murcia». Arte y poblamiento en el SE peninsular. Ant. y crist., V. Murcia, 353-402.

MAYA, J. L. (1977): «Precisiones en torno a las Termas del Campo de Valdés. Gijón (Asturias)», Bol. del Inst. de Estudios Asturianos, 92. Oviedo, 823-834.

MAYET, F. (1984): Les céramiques sigillées Hispaniques. París.

MAYET, F., y PICÓN, M. (1986): «Une sigillée phocéenne tardive ("Late Roman C ware”) et sa diffusion en occident». Figlina, 7. Lyón, 129-143.

MÉNDEZ ORTIZ, R. (1983-84): «Cerámica Late Roman C en Cartagena». Pyrenae, 19-20. Barcelona, 147157. 
MÉNDEZ ORTIZ. R. (1988): «El tránsito a la dominación bizantina en Cartagena: las producciones cerámicas de la plaza de los Tres Reyes». Arte y poblamiento en el SE peninsular. Ant. y crist., V. Murcia, 31-163.

NAVEIRO, J. (1991): «El comercio antiguo en el NW peninsular». Monografías Urxentes do Museu, 5. La Coruña.

Nieto. F. J. (1984): «Algunos datos sobre las importaciones de cerámica Phocaean Red Slip en la Península Ibérica". Papers in Iherian Archaeology. B.A.R. International Series, 193 (II). Oxford, 540-551.

NOLL.A-BRUFAU, J. M. (1984): «Excavaciones recientes de la ciudadela de Roses. El edificio Bajo-Imperial». Papers in Iherian Archaeology. B.A.R. International Series, 193 (II). Oxford, 430-459.

O'Riordain, S. P. (1942): The excavation of a large earthen Ring-Fort at Garranes, Co. Cork. Proceedings of the Royal Irish Academy, vol. XLVII. Sección C. No. 2. Dublín.

PALOL, P. de (1948): La cerámica estampada romano cristiana. IV Congreso Arqueológico del Sudeste Español. Elche, 450-469.

PANElla, C. (1986): «Le anfore tardoantiche: centri di produzione e mercati preferenziali». Societá Romana III. "Gli merci, gli insediamenti. Bari, 251-271.

Paz Peralta, J. A. (1991): Cerámica de mesa romana de los siglos III al vi d.C. en la provincia de Zaragoza. Institución Fernando el Católico. Zaragoza.

PEACOCK, D. P. S., y WILLIAMS, D. F. (1986): «Amphorae and the Roman economy. An introductory guide». Logman Archaeological series. Londres.

Pereira MAIA, M. G. (1978): «Contributos para as cartas de distribuçao em Portugal de "sigillata luzente" e da "Late Roman C ware"». Actas das III Jornadas Arqueológicas, vol. I. Lisboa, 295-307.

PÉREZ BONET, M.a A. (1988): «La economía tardorromana del sureste peninsular: el ejemplo del puerto de Mazarrón (Murcia)». Arte y poblamiento en el SE peninsular. Ant. y crist., V. Murcia, 471-541.

PÉRez LoSADA, F. (1991): «Noville (Franza, Murgados, A Coruña)». Arqueoloxia. Informes, 2. Campaña de 1988. Xunta de Galicia, 87-91.

PONSICH, M. (1980): «El teatro de Belo». N.A.H., 10. Madrid, 307-334.

REDDE, M. (1979): «La navigation au large des côtes atlantiques de la Gaule à l'époque romaine». $M E$ FRA, 91. ROMA, 481-489.

REYNOLDS, P. (1984): «African Red Slip ware and late roman imports in Valencia». B.A.R. International Series, 193. Oxford, 474-537.

REYNOLDS, P. (1987): El yacimiento tardorromano de Lucentum (Benalúa-Alicante): las cerámicas finas. Catálogo de fondos del Museo Arqueológico (II). Alicante.

RIGAUd DE SousA, J. J. (1966-67): Cerâmica estampada de Braga. Arquivo de Beja, XXIII-XXIV. Beja, 143-150.

RiGOIR, J. (1968): «Les sigillées paléochrétiennes grises et orangées». Gallia, XXVI (1). París, 177-244.

RIGOIR, J. y Y. (1971): «Les dérivées des sigillées paléochrétiennes en Espagne». Rivista di Studi Liguri. XXXVII. Bordighera, 31-68.

RigoIR, Y., y J. (1981): «Chrismes et croix sur les derivées des sigillées paléochétiennes». Rivista di Studi Liguri, XLVII (1-4). "Omagio a N. Lamboglia". Bordighera, 162-188.

RigOIR, J.; RigOIR, Y., y MEFFRE, J. F. (1973): «Les dérivés des sigillées paléochrétiennes du Groupe Atlantique», Gallia, XXXI. París, 207-263.

RILEY, J. A. (1976): «Late Amphora». En HumphreY, J. H. (ed.): Excavations at Carthage conducted by the University of Michigan, 1975. Vol. I. Ann Harbour, 114-120.

RILEY, J. A. (1982): New light on relations between the Eastern Mediterranean and Carthage in the Vandal and Byzantine periods: the evidence from the University of Michigan Excavations. Actes du colloque sur la céramique Antique, Carthage-1980. C.E.D.A.C. Cartago, 111-122.

ROLDÁN, B.; LÓPEZ, M., y VIDAL, M. (1991): «Contribución a la historia económica de Carthago Nova durante los siglos V y VI d.C.: el vertedero urbano de la calle Palas». Arte, sociedad, economía y religión durante el Bajo Imperio y la Antigüedad tardía. Ant. y crist., VIII. Murcia, 305-319.

Romero CARnicero, M. A. (1974): Aportación al estudio de la distribución en la Península Ihérica de 
la cerámica romano-visigoda con decoración estampada. Actas del III C.N.A. Porto, 1974. Zaragoza.

SAlomonson, J. W. (1968): "Etudes sur la céramique romaine d'Afrique. Sigillée claire et céramique commune de Henchir el Ouiba (Raqqada) en Tunise central». Bulletin Antieke Beschaving. XLIII. Roma.

SERRANO, E., y Luque, A. de (1980): «Memoria de la segunda y tercera campaña de excavaciones de la villa romana de Manguarra y San José. Cártama (Málaga)». N.A.H., 8. Madrid, 255-396.

SIRET, L. (1906): Villaricos y Herrerías. Antigïedades púnicas, romanas, visigóticas y árahes. Memorias de la Real Academia de la Historia. Madrid (facsímil editado en 1985).

Solana SaInZ, J. M.a(1977): Flaviohriga (Castro Urdiales). Universidad de Valladolid. Centro de estudios montañeses. Santander.

TORTORELLA, S. (1982): La sigillata africana a Cartagine fra il 400 d.C. e la conquista vandala: $i$ dati dello scavo della missione archeologica italiana. Actes du colloque sur céramique ántique, Carthage, 1980. C.E.D.A.C. Cartago, 125-139.

TORTORELlA, S. (1986): «La ceramica fine da mensa africana dal V al VIl secolo d.C.». Societá romana III. "Gli comerci, gli insediamenti». Bari, 211-225.

VAQUERIZO, D.; MURILlO, J. F., y QUESADA, F. (1991): «Avance a la prospección arqueológica de la Subbética: la depresión Priego-Alcaudete». Anales Arqueología Cordobesa, 2. Córdoba, 117-170.

VÁzQueZ DE LA Cueva, A. (1985): «Sigillata africana en Augusta Emérita». Monografías Emeritenses, 3. Museo Nacional de Arte Romano. Asociación de Amigos del Museo. Mérida.

VV.AA. (1981): Atlante delle forme ceramiche I. Ceramica fine romana nell bacino mediterraneo (medio e tardo impero). Enciclopedia dell'Arte antica classica e orientale. Roma.

VV.AA. (1989): «Un abocador del segle V d.C. en el fórum provincial de Tárraco». Memóries d'excavació, 2. Taller Escola d'Arqueologia. Tarragona.

WAAGE, F. O. (1933): «The roman and byzantine pottery. The american excavations in the athenian Agora». Hesperia, II. New Jersey, 279-328.

WILliamS, D. F. (1982): The petrology of certain byzantine amphorae: some suggestions as to origins. Actes du Colloque de Céramique Antique. Carthage, 1980. C.E.D.A.C. Cartago, 99-110.

ZEISS, H. (1933): «Spätrömische stempelverzierte Keramik aus Portugal und Spanien». Homenagem a Martíns Sarmento. Revista de Guimarâes. Guimarâes, 467-472. 